\title{
Testing the effect of the rock record on diversity: a multidisciplinary approach to elucidating the generic richness of sauropodomorph dinosaurs through time
}

\author{
Philip D. Mannion ${ }^{1 *}$, Paul Upchurch ${ }^{1}$, Matthew T. Carrano ${ }^{2}$ and Paul M. Barrett ${ }^{3}$ \\ ${ }^{1}$ Department of Earth Sciences, University College London, Gower Street, London, WC1E 6BT, UK \\ ${ }^{2}$ Department of Paleobiology, National Museum of Natural History, Smithsonian Institution, P.O. Box 37012, Washington, DC 20013-7012, \\ USA \\ ${ }^{3}$ Department of Palaeontology, The Natural History Museum, Cromwell Road, London, SW7 5BD, UK
}

(Received 07 October 2009; revised 24 March 2010; accepted 29 March 2010)

\begin{abstract}
The accurate reconstruction of palaeobiodiversity patterns is central to a detailed understanding of the macroevolutionary history of a group of organisms. However, there is increasing evidence that diversity patterns observed directly from the fossil record are strongly influenced by fluctuations in the quality of our sampling of the rock record; thus, any patterns we see may reflect sampling biases, rather than genuine biological signals. Previous dinosaur diversity studies have suggested that fluctuations in sauropodomorph palaeobiodiversity reflect genuine biological signals, in comparison to theropods and ornithischians whose diversity seems to be largely controlled by the rock record. Most previous diversity analyses that have attempted to take into account the effects of sampling biases have used only a single method or proxy: here we use a number of techniques in order to elucidate diversity. A global database of all known sauropodomorph body fossil occurrences (2024) was constructed. A taxic diversity curve for all valid sauropodomorph genera was extracted from this database and compared statistically with several sampling proxies (rock outcrop area and dinosaur-bearing formations and collections), each of which captures a different aspect of fossil record sampling. Phylogenetic diversity estimates, residuals and sample-based rarefaction (including the first attempt to capture 'cryptic' diversity in dinosaurs) were implemented to investigate further the effects of sampling. After 'removal' of biases, sauropodomorph diversity appears to be genuinely high in the Norian, Pliensbachian-Toarcian, Bathonian-Callovian and Kimmeridgian-Tithonian (with a small peak in the Aptian), whereas low diversity levels are recorded for the Oxfordian and Berriasian-Barremian, with the Jurassic/Cretaceous boundary seemingly representing a real diversity trough. Observed diversity in the remaining Triassic-Jurassic stages appears to be largely driven by sampling effort. Late Cretaceous diversity is difficult to elucidate and it is possible that this interval remains relatively under-sampled. Despite its distortion by sampling biases, much of sauropodomorph palaeobiodiversity can be interpreted as a reflection of genuine biological signals, and fluctuations in sea level may account for some of these diversity patterns.
\end{abstract}

Key words: dinosaurs, diversity, extinction, macroevolution, rarefaction, residuals, rock record, sampling bias, sauropodomorphs, sea level.

\section{CONTENTS}

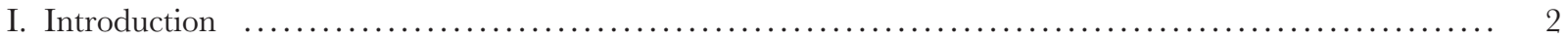

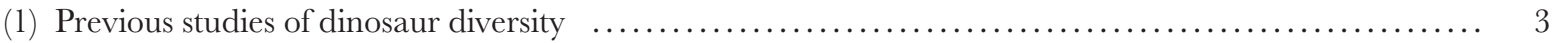

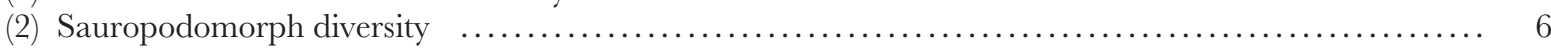

* Address for correspondence: (Tel: +44 0207679 30165; E-mail: p.mannion@ucl.ac.uk). 


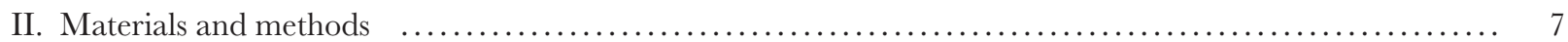

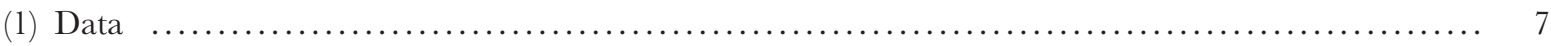

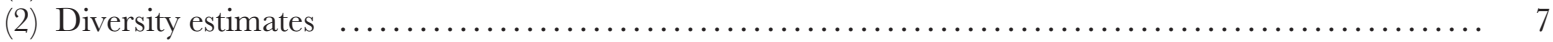

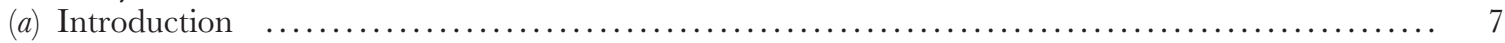

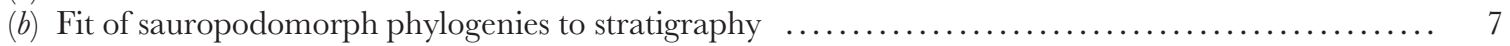

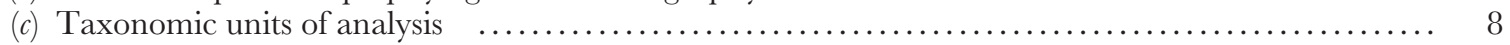

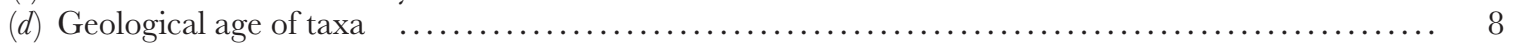

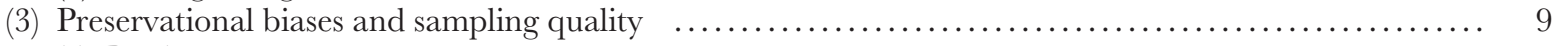

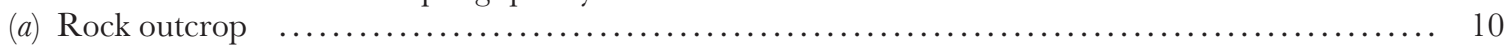

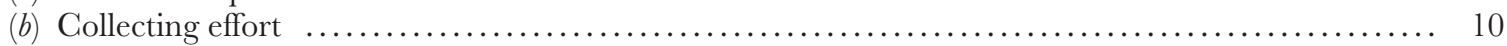

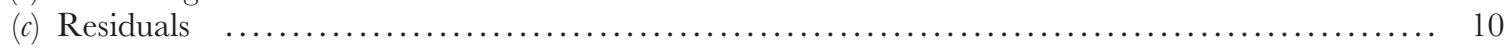

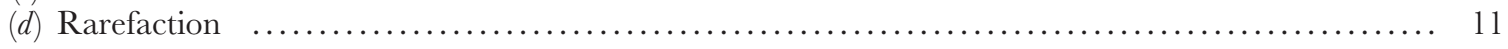

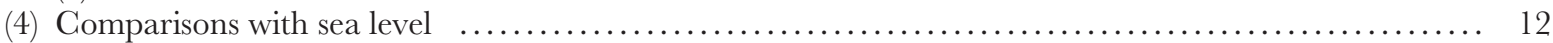

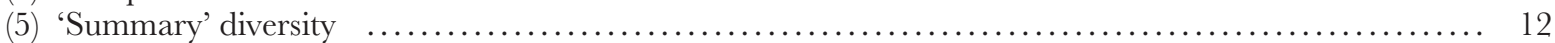

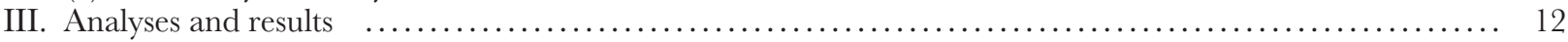

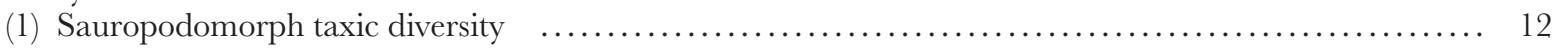

(2) Statistical comparisons between phylogenetic and taxic diversity $\ldots \ldots \ldots \ldots \ldots \ldots \ldots \ldots \ldots \ldots \ldots \ldots \ldots \ldots$

(3) Statistical comparisons between diversity and sampling proxies $\ldots \ldots \ldots \ldots \ldots \ldots \ldots \ldots \ldots \ldots \ldots \ldots$

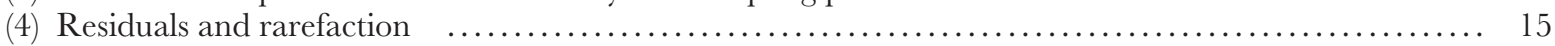

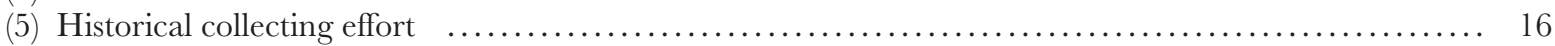

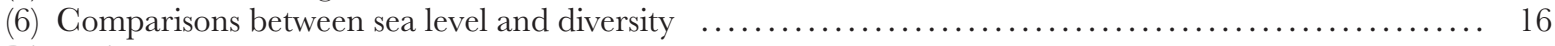

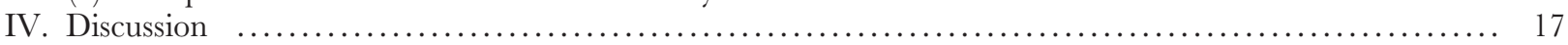

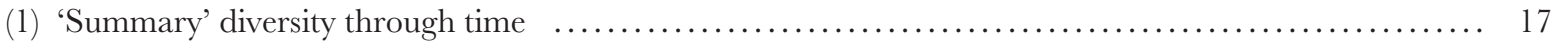

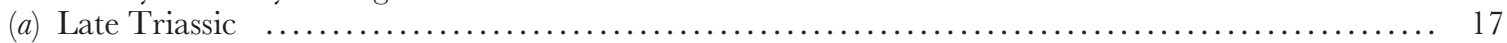

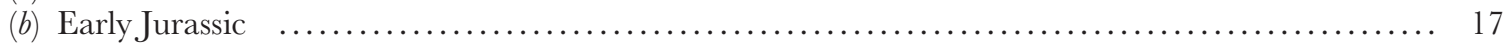

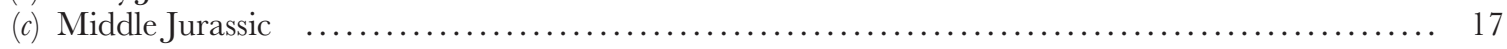

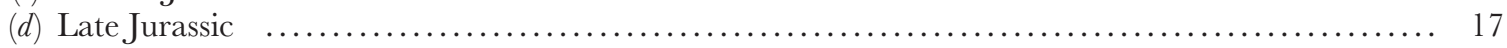

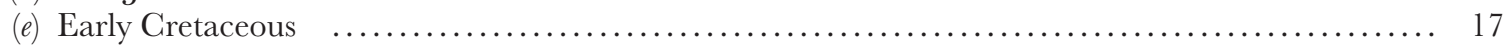

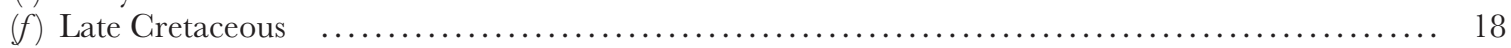

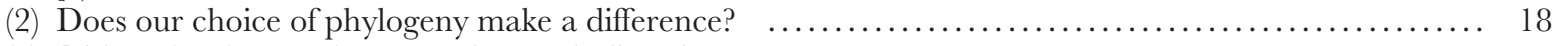

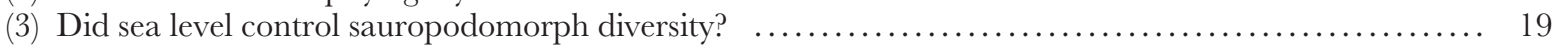

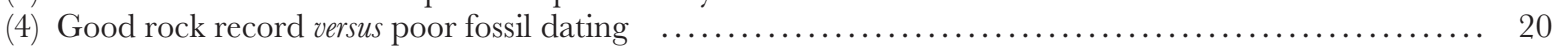

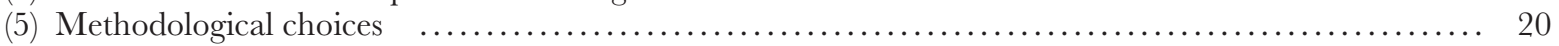

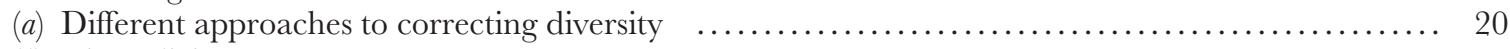

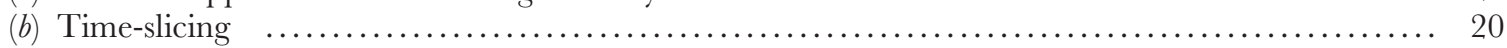

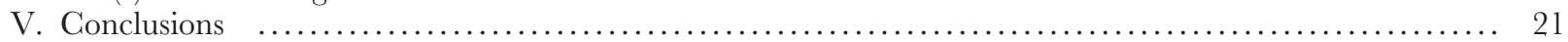

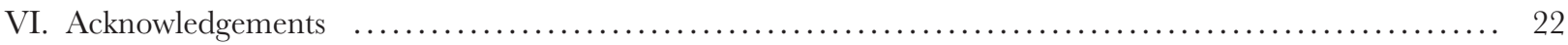

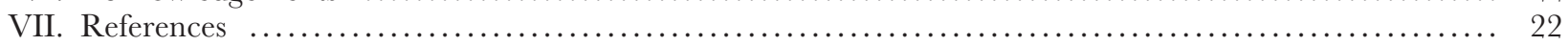

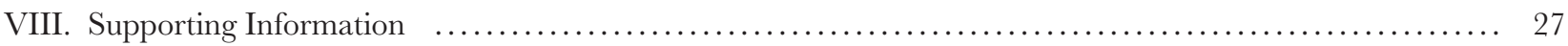

\section{INTRODUGTION}

Deducing diversity patterns through time is an important element in understanding the macroevolutionary history of a group of organisms. The recovery of peaks and troughs in the diversity curve, and knowledge of their magnitude and sequence, enables us to assess the tempo and mode of evolution in any clade, as well as recognise major events in the history of life, including adaptive radiations and extinctions (Valentine, 1985; Jablonski, Erwin \& Lipps, 1996; Jablonski, 2005). In addition, detailed knowledge of these patterns allows testing of potentially important evolutionary processes, such as competition and co-evolution, over extended temporal scales (e.g. Bakker, 1978; Vermeij, 1983; Collinson \& Hooker, 1991; Benton, 1996; Barrett \& Upchurch, 2005; Butler et al., 2009a, b, c). There are several ways in which palaeobiodiversity can be defined and thus measured (Smith, 1994); here, we use 'diversity' in the sense of taxonomic richness (e.g. the number of species, genera, etc. that occur during a given time period).

The study of dinosaur diversity has proved to be a fruitful, yet controversial, area of research into Mesozoic palaeobiodiversity patterns (Dodson, 1990; Haubold, 1990; Dodson \& Dawson, 1991; Sereno, 1997, 1999; Fastovsky et al., 2004; Taylor, 2006; Wang \& Dodson, 2006; Carrano, 2008a; Lloyd et al., 2008; Barrett, McGowan \& Page, 2009). There have also been several analyses investigating the diversity of particular clades within Dinosauria (Hunt et al., 1994; Lockley et al., 1994; Weishampel \& Jianu, 2000; Barrett \& Willis, 2001; Barrett \& Upchurch, 2005; Upchurch \& Barrett, 2005; Mannion, 2009b). The majority of these studies were based on taxonomic diversity records (i.e. direct readings of the fossil record by counting the numbers of genera or families that can be observed through 
geological time). Seven of these analyses (Sereno, 1997, 1999; Weishampel \& Jianu, 2000; Upchurch \& Barrett, 2005; Lloyd et al., 2008; Barrett et al., 2009; Mannion, 2009b) incorporated phylogenetic relationships into the diversity estimates. A second subset of studies (Fastovsky et al., 2004; Barrett \& Upchurch, 2005; Upchurch \& Barrett, 2005; Wang \& Dodson, 2006; Carrano, 2008a; Lloyd et al., 2008; Barrett et al., 2009; Mannion, 2009b; Mannion \& Upchurch, 2010b) have attempted to take into account sampling biases that might affect any reading of the dinosaur fossil record. However, each of these analyses utilised only a subset of the available techniques for elucidating diversity patterns, making it unclear how the results would have differed if alternative methods had been applied; consequently, there are few examples where we can compare the performances of different methods side-by-side.

Herein, we present the results of a multi-method approach to the identification and removal of sampling biases in palaeodiversity analyses. We utilise a recently developed and virtually comprehensive dataset to analyse sauropodomorph dinosaur palaeodiversity using the full spectrum of competing techniques. This paper builds on previous sauropodomorph diversity analyses, particularly those of Upchurch \& Barrett (2005) and Barrett et al. (2009). A taxic diversity estimate for all valid sauropodomorph taxa and several competing phylogenies are plotted onto stratigraphic range charts in order to produce and compare diversity curves. We investigate a number of preservational biases potentially affecting sauropodomorph diversity using a variety of methods (including residuals and rarefaction), and examine whether peaks and troughs in diversity correlate with potential causal factors such as sea level.

Sauropodomorpha is the sister group of Theropoda, which together comprise the Saurischia (Fig. 1; Weishampel, Dodson \& Osmólska, 2004b, and references therein). Several aspects of these large-bodied herbivores make them particularly suitable for examining and testing long-term diversity patterns. First, sauropodomorph remains have been found on all continents and by the Middle Jurassic, at the latest, they had achieved a global distribution (McIntosh, 1990; Upchurch, 1995; Wilson \& Sereno, 1998; Upchurch, Hunn \& Norman, 2002; Upchurch, Barrett \& Dodson, 2004; Weishampel et al., 2004a). Second, they were a significant and diverse part of Mesozoic terrestrial ecosystems (Fig. 2) until their extinction at the end of the Cretaceous along with the other non-avian dinosaurs; this evolutionary history spans 160 million years (Myr). Finally, the clade includes the largest terrestrial animals of all time (Wilson, 2002; Upchurch et al., 2004), with Argentinosaurus (body mass exceeding 70 tonnes; Mazzetta, Christiansen \& Fariña, 2004) a notable example, and as such has a high preservation potential.

\section{(1) Previous studies of dinosaur diversity}

The earliest modern studies of dinosaur diversity focused on determining the raw numbers of dinosaur taxa present during the Mesozoic (Dodson, 1990; Haubold, 1990). These analyses agreed on a general pattern that included three

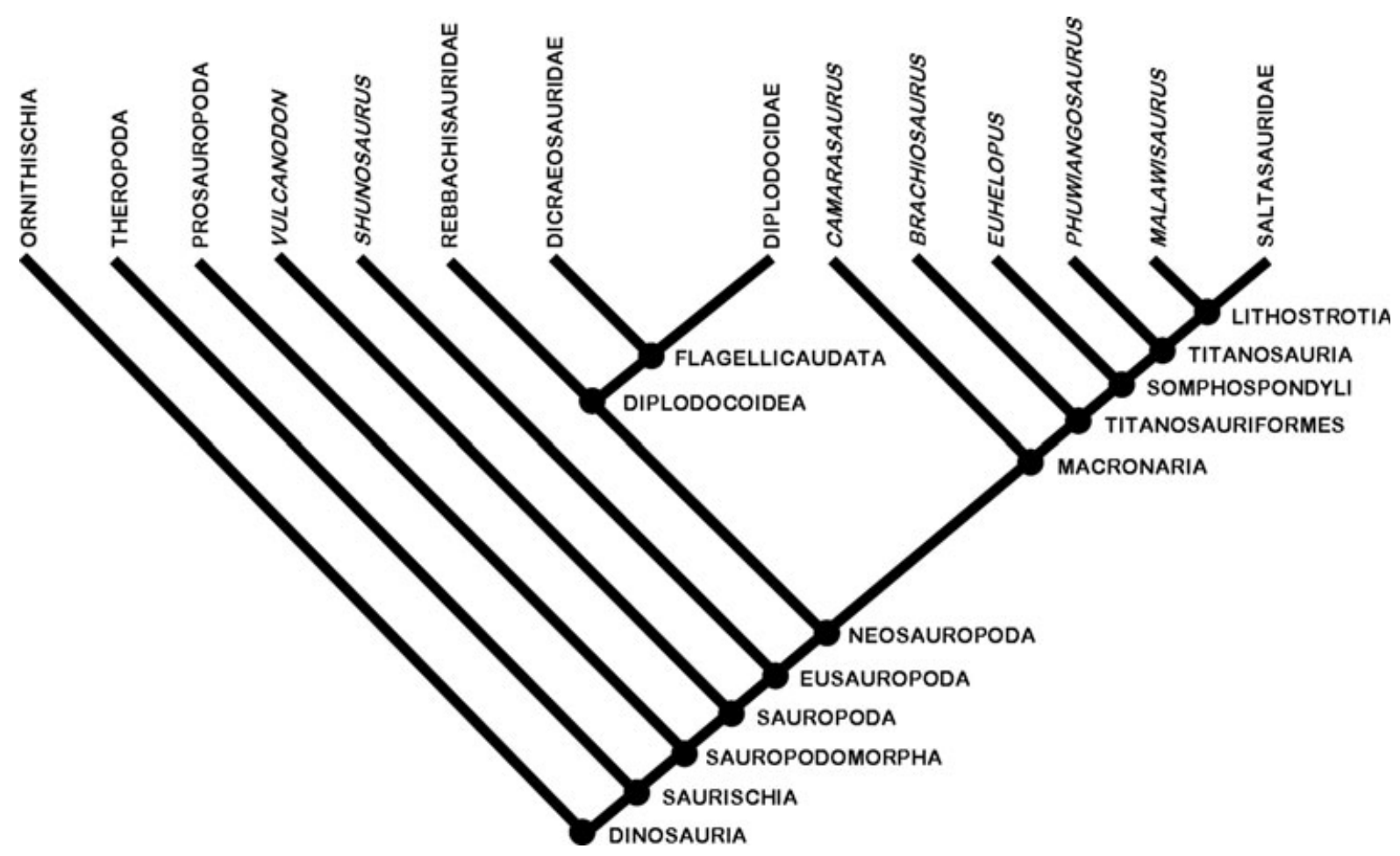

Fig. 1. Simplified cladogram showing dinosaur inter-relationships, the main sauropodomorph lineages, and the stem- and node-based names currently in use (modified from Wilson, 2002; Wilson \& Upchurch, 2003, 2009; Upchurch et al., 2004). 
A

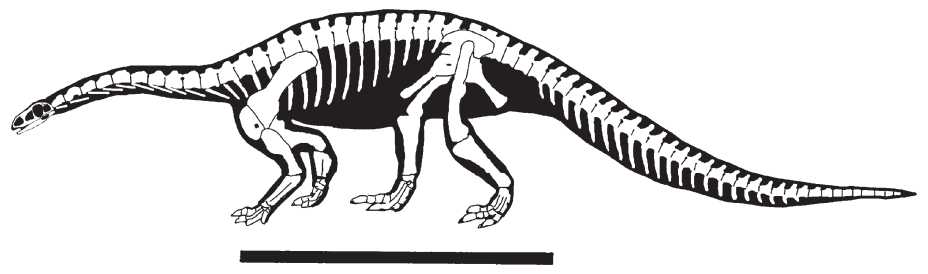

B

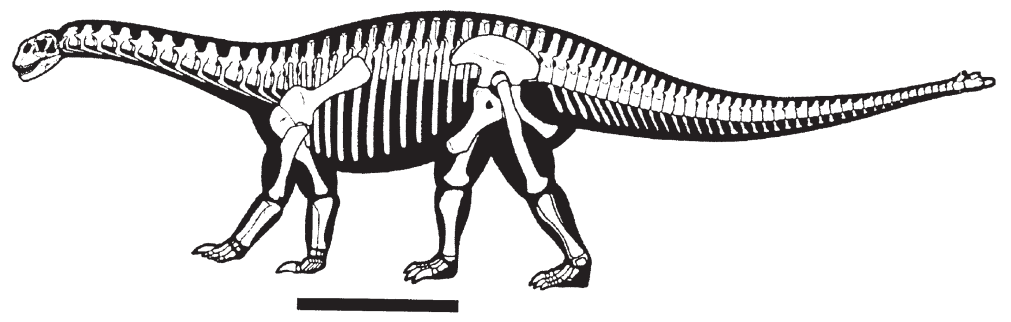

c

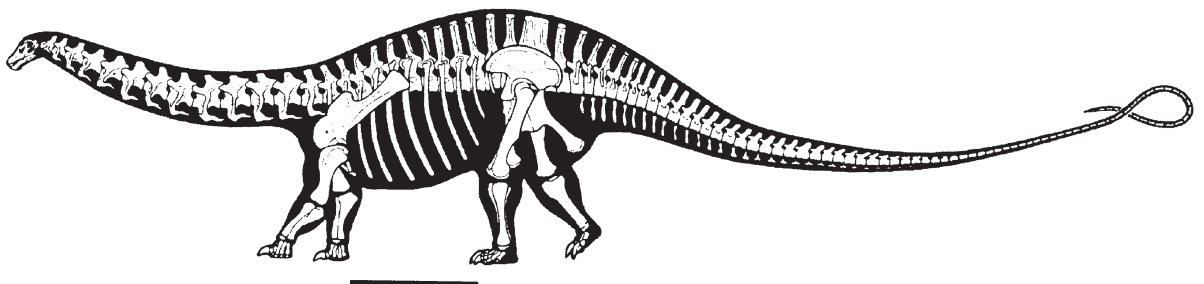

D

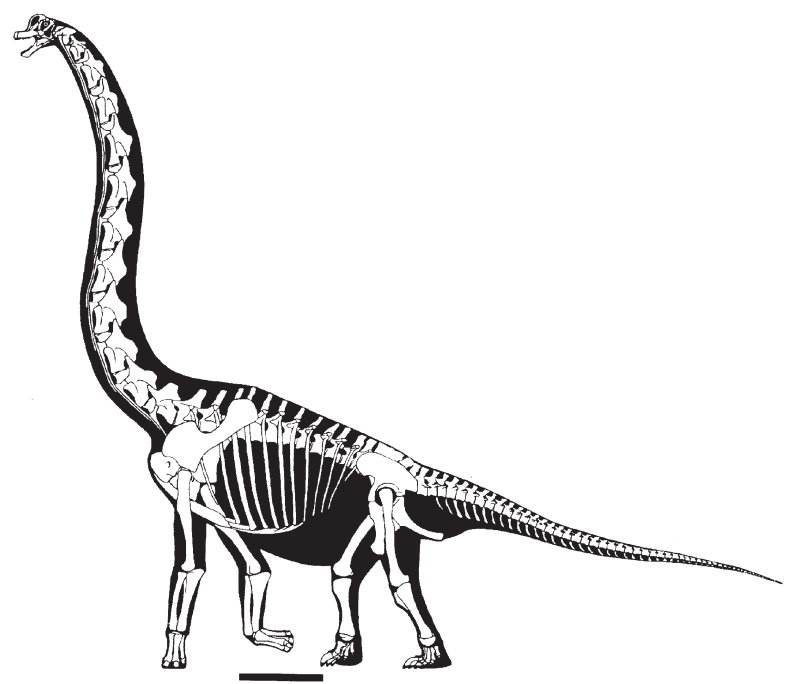

Fig. 2. Skeletal outlines of four sauropodomorphs: (A) Plateosaurus, (B) Shunosaurus, (C) Apatosaurus, (D) Brachiosaurus (after Wilson \& Sereno, 1998; Galton \& Upchurch, 2004a; Upchurch et al., 2004). Scale bars $=2 \mathrm{~m}$.

diversity peaks (Late Triassic, Late Jurassic and Late Cretaceous; Fig. 3A), which were suggested to be at least partly tied to sea level cycles; however, they presented opposing views on the specific relationships between diversity and sea level. Both studies acknowledged the importance of sampling and other biases, but were unable to assess them quantitatively.

Sereno $(1997,1999)$ produced time-calibrated cladograms for all dinosaurs and used these to assess diversity. This early attempt to assess phylogenetic diversity confirmed that the appearance of basal ornithischians (heterodontosaurids) and basal sauropodomorphs ('prosauropods') in the Late Triassic resulted in a small diversity peak, with sauropod diversity reaching its apex in the Late Jurassic (Fig. 3B). Overall, dinosaur diversity was low in the earliest Cretaceous, followed by a general increase in the mid-Cretaceous and a large rise during the Campanian-Maastrichtian (83.5-65.5 Myr; Fig. 3B): ceratopsians and ornithopods achieved their greatest diversity at this time (Sereno, 1999). Although these two studies (Sereno, 1997, 1999) took into account the effects of available rock outcrop area on diversity, peaks were considered as genuine biological events, whereas troughs in 


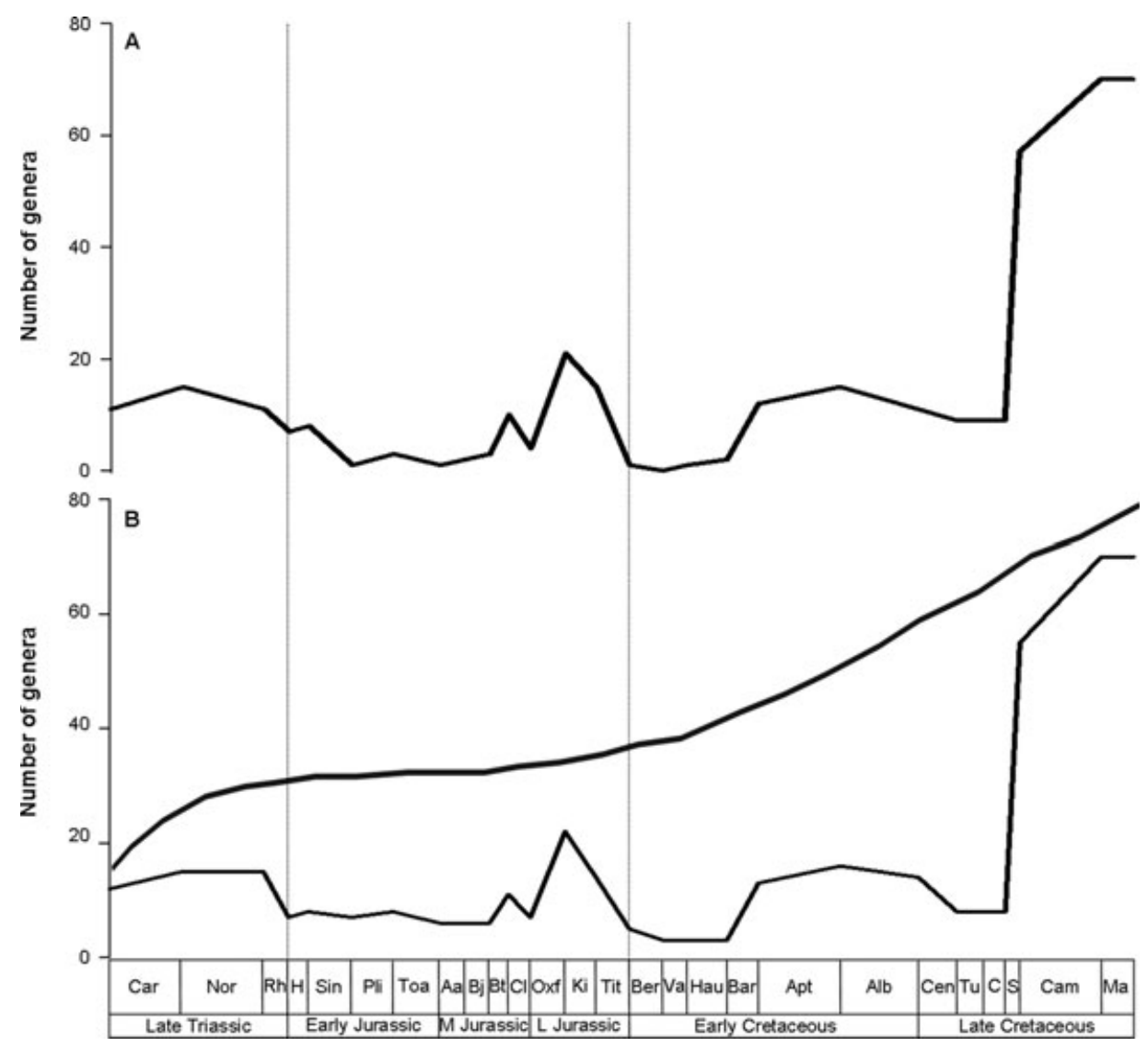

Fig. 3. Summary dinosaur diversity curves based on counts of numbers of genera through time: (A) modified from Dodson (1990); (B) modified from Sereno (1999). The upper curve in B represents an estimated curve of diversity after taking into account available outcrop area (after Sereno, 1999). Abbreviations: Car = Carnian, Nor = Norian, Rh $=$ Rhaetian, H = Hettangian, Sin $=$ Sinemurian, Pli = Pliensbachian, Toa = Toarcian, $\mathrm{Aa}=$ Aalenian, $\mathrm{Bj}=$ Bajocian, $\mathrm{Bt}=$ Bathonian, $\mathrm{Cl}=\mathrm{Callovian}, \mathrm{Oxf}=$ Oxfordian, $\mathrm{Ki}=$ Kimmeridgian, Tit = Tithonian, Ber = Berriasian, Va = Valanginian, Hau = Hauterivian, Bar = Barremian, Apt $=$ Aptian, Alb = Albian, Cen = Cenomanian, $\mathrm{Tu}=$ Turonian, $\mathrm{C}=$ Coniacian, $\mathrm{S}=$ Santonian, Cam $=\mathrm{Campanian}, \mathrm{Ma}=$ Maastrichtian.

diversity were interpreted as sampling biases. Consequently, the resultant estimated diversity curve showed a gradual diversity increase during the Triassic-Jurassic, before a relatively rapid increase throughout the Cretaceous (Fig. 3B). A similar pattern was recovered by Lloyd et al. (2008), who constructed a time-calibrated dinosaurian supertree which was used to estimate diversification rates across the clade. Several subsequent studies focused on estimating diversity patterns for individual clades of dinosaurs (e.g. Weishampel \& Jianu, 2000; Barrett \& Willis, 2001), whereas others attempted to investigate biotic turnover immediately prior to the end-Cretaceous extinction (e.g. Fastovsky et al., 2004; Wang \& Dodson, 2006; Carrano, 2008a).

More recently, several workers have begun to address explicitly how biases in sampling, phylogeny and the fossil record might impact perceptions of dinosaur diversity. Barrett et al. (2009) assessed dinosaur diversity (including Mesozoic birds) based on taxic and phylogenetic curves for genera and species. In order to test whether geological sampling biases impacted the shapes of these curves, these authors constructed a diversity model utilising the residuals method of Smith \& McGowan (2007; see Section II). This model predicted the expected genus richness for each dinosaur clade using the number of dinosaurbearing formations (DBFs) (see Table 1 for a summary of abbreviations used herein) present in each time interval as a geological proxy for the amount of dinosaur-bearing rock available through time ( $c f$. Peters \& Foote, 2001). Statistical comparisons between these models and the observed diversity curves suggested that ornithischian and theropod diversity patterns were significantly correlated with fluctuations in the rock record [as also suggested by Weishampel \& Jianu (2000) and Upchurch \& Barrett (2005)]. However, sauropodomorph diversity was largely independent of changes in the number of DBFs, potentially reflecting genuine evolutionary events (Barrett et al., 2009; see also Upchurch \& Barrett, 2005). These results suggest that it may be possible to analyse and interpret certain genuine biological aspects of sauropodomorph diversification. Below we outline the current consensus view on sauropodomorph diversity before presenting a more detailed investigation into the effects of sampling on the genus richness of this clade. 
Table 1. List of abbreviations used in the text

\begin{tabular}{ll}
\hline \hline Abbreviation & \multicolumn{1}{c}{ Definition } \\
\hline BPDE & Barrett et al. (2009) phylogenetic diversity estimate \\
BTDE & Barrett et al. (2009) taxic diversity estimate \\
DBCs & Dinosaur-bearing collections \\
DBFs & Dinosaur-bearing formations \\
LPDE & Lloyd et al. (2008) phylogenetic diversity estimate \\
MDE & Modelled diversity estimate \\
Myr & Million years \\
NOOs & Numbers of opportunities to observe \\
PDE & Phylogenetic diversity estimate \\
TDE & Taxic diversity estimate \\
TDEP & Pruned taxic diversity estimate \\
TDE & Western European taxic diversity estimate \\
UPDE & Upchurch et al. (2004, 2007) phylogenetic \\
& diversity estimate \\
WPDE & Wilson (2002) phylogenetic diversity estimate \\
YPDE & Yates (2007) phylogenetic diversity estimate \\
\hline \hline
\end{tabular}

\section{(2) Sauropodomorph diversity}

The earliest known sauropodomorphs are Saturnalia and Panphagia from the early Carnian (228 Myr; Late Triassic) of Brazil and Argentina, respectively (Langer et al., 1999; Martinez \& Alcober, 2009). An earlier record from the Middle Triassic of Madagascar (Flynn et al., 1999) has since been shown to represent a non-dinosaurian archosauromorph (Flynn et al., 2008). An early diversity peak comprised of basal sauropodomorphs and 'prosauropods' (e.g. Thecodontosaurus, Mussaurus and Plateosaurus) in the Norian (216.5-203.6 Myr; Late Triassic) was followed by a drop in the Rhaetian (203.6-199.6 Myr), before a prominent Early Jurassic increase (Fig. 4; Weishampel \& Jianu, 2000; Barrett \& Upchurch, 2005; Barrett et al., 2009). Non-eusauropod sauropodomorphs (including 'prosauropods'; Fig. 1) became extinct prior to the Middle Jurassic, coincident with the onset of a eusauropod radiation (Sereno, 1999; Barrett \& Upchurch, 2005). Note that these taxa became extinct regardless of whether they are considered monophyletic (e.g. Gauthier, 1986; Benton et al., 2000; Galton \& Upchurch, $2004 a$; Upchurch, Barrett \& Galton, 2007) or a paraphyletic assemblage (Yates, 2003, 2004, 2007; Yates \& Kitching, 2003); only the nature of this extinction may in some respects be a taxonomic artefact (see Forey et al., 2004).

Several studies have noted a Middle Jurassic peak in sauropod diversity (Hunt et al., 1994; Barrett \& Willis, 2001; Upchurch \& Barrett, 2005), which may reflect a neosauropod radiation (Wilson \& Sereno, 1998; Figs 1, 4). The Oxfordian (161.2-155.7 Myr; early Late Jurassic) represents an apparent diversity trough (Upchurch \& Barrett, 2005; Barrett et al., 2009), while the remaining Late Jurassic stages (Kimmeridgian-Tithonian; 155.7-145.5 Myr) are typically thought to have represented the highest peak in diversity (Fig. 4) (Bakker, 1977, 1978; Horner, 1983; Weishampel \& Horner, 1987; Haubold, 1990; Hunt et al., 1994; Upchurch, 1995; Sereno, 1997, 1999; Wilson \& Sereno, 1998; Weishampel \& Jianu, 2000; Barrett \& Willis, 2001; Upchurch \& Barrett, 2005; Barrett et al., 2009), exemplified by well-known taxa such as Brachiosaurus and Diplodocus.

A prominent decline in the number of genera across the Jurassic/Cretaceous ( $\mathrm{J} / \mathrm{K})$ boundary (145.5 Myr) is implied by the apparently reduced species richness of the earliest Cretaceous (Fig. 4) (Hunt et al., 1994; Wilson \& Sereno, 1998; Upchurch \& Barrett, 2005; Barrett et al., 2009). Sauropods underwent a major diversification in the mid-Cretaceous (Fig. 4), with this radiation predominantly composed of titanosaurs (Salgado, Coria \& Calvo, 1997; Wilson \& Upchurch, 2003; Curry Rogers, 2005; Upchurch \& Barrett, 2005; Lloyd et al., 2008), as well as a small contribution from rebbachisaurid diplodocoids (Upchurch \& Barrett, 2005; Sereno et al., 2007; Mannion, 2009a) (Fig. 1). Diversity apparently dropped in the mid-Late Cretaceous before

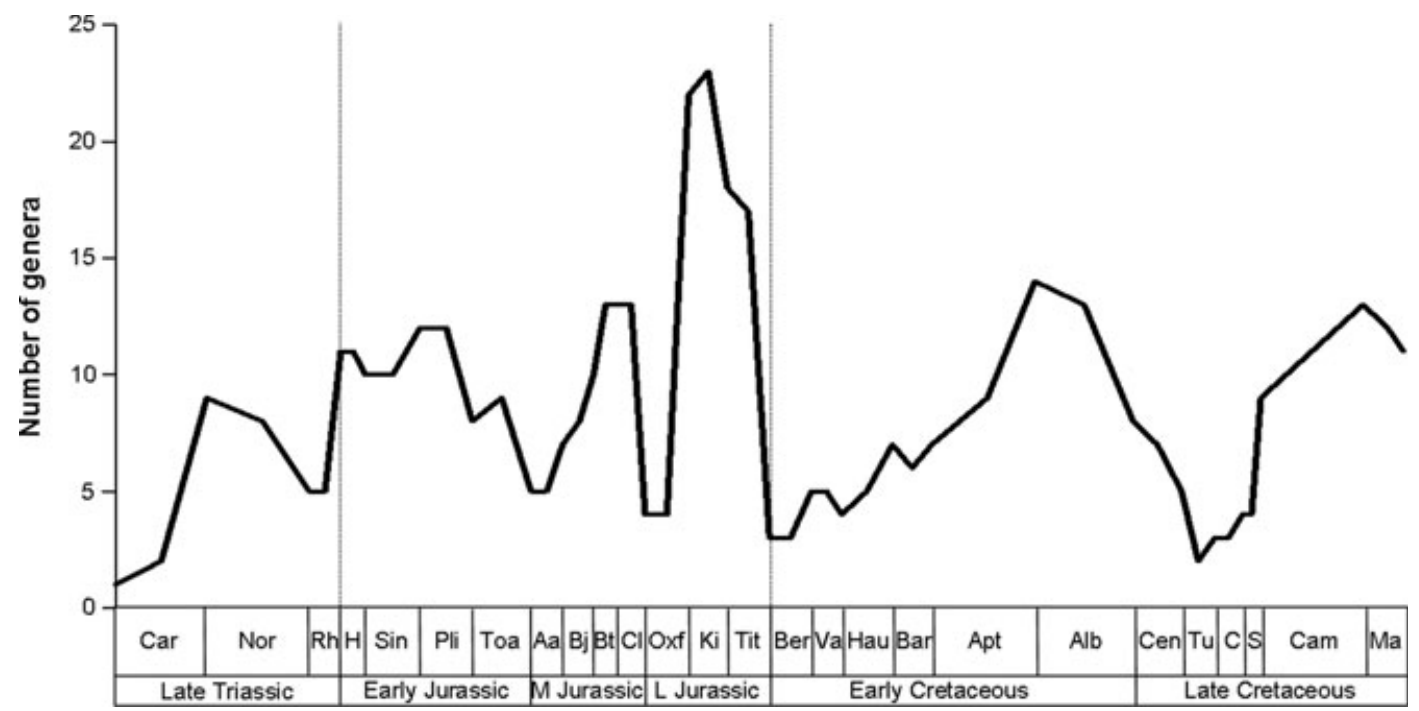

Fig. 4. Consensus of sauropodomorph diversity based primarily upon Upchurch \& Barrett (2005) and Barrett et al. (2009). See Fig. 3 for abbreviations. 
reaching another peak in the Campanian-Maastrichtian (83.5-65.5 Myr; Hunt et al., 1994; Weishampel \& Jianu, 2000; Barrett \& Willis, 2001; Upchurch \& Barrett, 2005), although this peak is smaller than that in the Late Jurassic. There is also evidence for a decline in sauropod diversity prior to their final extinction at the Cretaceous/Paleogene $(\mathrm{K} / \mathrm{P})$ boundary (65.5 Myr; Fig. 4) (Upchurch \& Barrett, 2005).

A number of these diversity peaks and troughs have been noted as corresponding with rises and falls in sea level (Haubold, 1990; Hunt et al., 1994; Upchurch \& Barrett, 2005) and it has been suggested that some of these intervals, at least, may potentially represent genuine (i.e. biotic) diversity signals rather than purely the effects of taphonomic biases (Upchurch \& Barrett, 2005; Barrett et al., 2009).

\section{MATERIALS AND METHODS}

\section{(1) Data}

A global database of all known sauropodomorph body fossil occurrences was constructed, consisting of 2024 individuals (available as online Appendix). These data were collected primarily from the literature (including Weishampel et al., 2004a, b), supplemented with data from The Paleobiology Database (www.paleodb.org; Carrano, 2008b) and personal observations during museum visits (see online Appendix). The minimum number of individuals was estimated for each discrete geographic locality and stratigraphic level (see Mannion \& Upchurch, 2010a). A compilation of all valid sauropodomorph taxa (175, as of September 2008) was extracted from this database (see online Appendix), based on updates made to Galton \& Upchurch (2004a) and Upchurch et al. (2004). The phylogenies of Wilson (2002), Upchurch et al. (2004, 2007), Yates (2007) and Lloyd et al. (2008) have all been utilised.

\section{(2) Diversity estimates}

\section{(a) Introduction}

There are two main methods for measuring diversity. First, the 'taxic' approach (Levinton, 1988) defines the total geological range of each taxon and sums the numbers of taxa present in each time interval to produce a diversity curve. This approach has the benefits of: (1) allowing all taxa to be incorporated, (2) being computationally simple to implement and (3) not requiring knowledge of detailed phylogenetic relationships. However, the taxic method has been strongly criticised for its reliance on what is often considered an incomplete and biased fossil record, leading to the development of a second method, the phylogenetic approach (Novacek \& Norell, 1982; Norell \& Novacek, 1992a, b; Smith, 1994). This method calibrates the phylogenetic relationships between taxa against stratigraphy. It follows the bifurcation model of speciation (Hennig, 1965) in that sister taxa must have equal first appearance times; thus, the first appearance times of taxa are extended back in time to that of the oldest known sister taxon occurrence, creating 'ghost' lineages or ranges, which reflect gaps in the fossil record (Norell, 1992, 1993). There are several criticisms of the phylogenetic method, however. For example, by only correcting for the first appearance times of taxa (i.e. through 'ghost' lineages), the phylogenetic method introduces an asymmetrical bias by not also extending extinction times forwards (Wagner, 1995, 2000b; Foote, 1996). Additionally, the assumption that ancestral taxa are rarely found in the fossil record (Lane, Janis \& Sepkoski, 2005) means that they are absent among the terminal taxa of a phylogeny (Benton \& Storrs, 1994). Also, when misdiagnosed ancestors are included in phylogenies, the addition of ghost lineages may over-inflate diversity estimates (Lane et al., 2005).

The use of the taxic approach has not been abandoned: many workers have utilised enhanced statistical techniques in attempts to resolve its problems (e.g. Alroy et al., 2008). Thus, both the taxic and phylogenetic methods have been applied here; through this pluralistic approach we hope to overcome the disadvantages of both methods (Wagner, 1995; Foote, 1996; Lane et al., 2005; Upchurch \& Barrett, 2005).

\section{(b) Fit of sauropodomorph phylogenies to stratigraphy}

Before we use phylogenies to reconstruct diversity, we need to have some idea of how well they fit stratigraphy in order to see how closely they sample and reflect the fossil record. Phylogenies are generally obtained solely from biological data and are usually independent of temporal information (Norell, 1996). Thus, by mapping cladograms onto stratigraphic range charts we can combine two independent methods for understanding the evolution of a group of organisms (see Pol \& Norell, 2006, and references therein). Most dinosaur datasets have been demonstrated to show extremely high congruence between phylogeny and stratigraphy (Brochu \& Norell, 2000; Wilson, 2002; Rauhut, 2003; Pol \& Norell, 2006; Wills, Barrett \& Heathcote, 2008), leading Wills et al. (2008) to comment that our knowledge of the dinosaur fossil record is more than adequate for investigating temporal patterns of dinosaur diversity. Regions of diversity curves where different phylogenies produce comparable results may represent better constrained time periods, whereas incompatible areas may represent more poorly understood portions of Sauropodomorpha (either in terms of missing lineages, low-resolution dating and/or a poor rock record, or differing interpretations of the same material; Benton, 2001; Wills, 2002; Smith \& McGowan, 2007); consequently, a number of independent phylogenies have been utilised in this study. Diversity has been plotted against the geological timescale of Gradstein, Ogg \& Smith (2005), with origins and stratigraphic ranges dated to substage level (see Section II. 2d).

Two non-parametric statistical methods are applied to assess the degree of correlation between each of the diversity curves (and are also used for comparing diversity with sampling biases: see below). Spearman's rank correlation coefficient compares the order of appearance of data points on two axes, whereas Kendall's tau rank correlation 
coefficient assesses whether the curves from two datasets are in phase with one another (Hammer \& Harper, 2006). All statistics were calculated using PAST (Hammer, Harper \& Ryan, 2001). Tables 2-4 list all of the comparisons made and the statistical results for each test.

\section{(c) Taxonomic units of analysis}

Several authors have highlighted problems with using the unit of species for estimating diversity (e.g. Smith, 2001), with Robeck, Maley \& Donoghue (2000, p. 186) noting that it 'results in one of the worst correlations with underlying lineage diversity' when sampling is poor. In the present dataset, however, the distinction between genus and species is a minor concern: the majority (94\%) of sauropodomorph genera are monospecific and thus there can be little difference between species- and genus-level diversity curves (Upchurch \& Barrett, 2005). Indeed, genus and species diversity curves are strongly correlated for sauropodomorphs (P.M.B., unpublished data). Moreover, most large analyses of sauropodomorph phylogeny (except Lloyd et al., 2008) have been conducted at the genus level,

Table 2. Results of statistical analyses comparing the various diversity curves to one another. See Table 1 for an explanation of the abbreviations of diversity curves. When the time interval is not stated, the analysis was run for the Late Triassic-Cretaceous. $\mathrm{LT}=$ Late Triassic, $\mathrm{J}=$ Jurassic, EJ = Early Jurassic, $\mathrm{K}=$ Cretaceous, EK = Early Cretaceous, LK = Late Cretaceous, Bar $=$ Barremian, Maa = Maastrichtian. Statistically significant results are in bold

\begin{tabular}{|c|c|c|}
\hline Comparison & Spearman's $r s$ & Kendall's tau \\
\hline $\begin{array}{l}\text { UPDE versus YPDE } \\
\text { (LT-J) }\end{array}$ & $0.875(P<0.001)$ & $0.758(P<0.001)$ \\
\hline $\begin{array}{l}\text { UPDE versus WPDE } \\
(\mathrm{J}-\mathrm{K})\end{array}$ & $0.637(P<0.001)$ & $0.515(P<0.001)$ \\
\hline UPDE versus TDE & $0.321(P=0.009)$ & $0.260(P=0.006)$ \\
\hline $\begin{array}{l}\text { UPDE versus TDE } \\
\text { (LT-J) }\end{array}$ & $0.877(P<0.001)$ & $0.730(P<0.001)$ \\
\hline UPDE versus TDE (K) & $-0.373(P=0.067)$ & $-0.286(P=0.077)$ \\
\hline $\begin{array}{l}\text { UPDE versus TDE } \\
\text { (Bar-Maa) }\end{array}$ & $0.301(P=0.228)$ & $0.233(P=0.258)$ \\
\hline TDE versus BTDE & $0.812(P<0.001)$ & $0.667(P<0.001)$ \\
\hline UPDE versus BTDE & $0.499(P=0.001)$ & $0.404(P=0.001)$ \\
\hline UPDE versus BPDE & $0.839(P<0.001)$ & $0.698(P<0.001)$ \\
\hline TDE versus BPDE & $0.264(P=0.073)$ & $0.198(P=0.064)$ \\
\hline UPDE versus LPDE & $0.444(P=0.001)$ & $0.331(P<0.001)$ \\
\hline LPDE versus TDE & $0.358(P=0.013)$ & $0.260(P=0.014)$ \\
\hline $\begin{array}{l}\text { LPDE versus TDE } \\
\text { (LT-J) }\end{array}$ & $0.639(P<0.001)$ & $0.470(P=0.001)$ \\
\hline LPDE versus TDE $(\mathrm{K})$ & $-0.080(P=0.732)$ & $-0.056(P=0.753)$ \\
\hline UPDE versus $\mathrm{TDE}_{\mathrm{P}}$ & $0.731(P<0.001)$ & $0.638(P<0.001)$ \\
\hline $\begin{array}{l}\text { UPDE versus } \text { TDE }_{\mathrm{P}} \\
(\mathrm{LT}-\mathrm{J})\end{array}$ & $0.601(P=0.002)$ & $0.493(P=0.002)$ \\
\hline UPDE versus TDE $_{\mathrm{P}}(\mathrm{K})$ & $0.835(P<0.001)$ & $0.745(P<0.001)$ \\
\hline $\mathrm{LPDE}_{\text {versus }} \mathrm{TDE}_{\mathrm{P}}$ & $0.360(P=0.008)$ & $0.245(P=0.013)$ \\
\hline $\begin{array}{l}\text { LPDE versus } \mathrm{TDE}_{\mathrm{P}} \\
\text { (LT-J) }\end{array}$ & $0.456(P=0.014)$ & $0.304(P=0.033)$ \\
\hline $\mathrm{LPDE}_{\text {versus }} \mathrm{TDE}_{\mathrm{P}}(\mathrm{K})$ & $0.306(P=0.137)$ & $0.217(P=0.160)$ \\
\hline
\end{tabular}

Table 3. Results of statistical analyses comparing diversity with preservational and sampling proxies. See Table 1 for an explanation of the abbreviations of diversity curves and proxies and Table 2 for other abbreviations. Statistically significant results are in bold

\begin{tabular}{|c|c|c|}
\hline Comparison & Spearman's rs & Kendall's tau \\
\hline UPDE versus DBFs & $-0.526(P<0.001)$ & $-0.334(P=0.001)$ \\
\hline $\begin{array}{l}\text { UPDE versus DBFs } \\
\text { (LT-EJ) }\end{array}$ & $0.112(P=0.717)^{\prime}$ & $0.121(P=0.610)$ \\
\hline UPDE versus DBFs (EJ) & $-0.733(P=0.048)$ & $-0.537(P=0.100)$ \\
\hline TDE versus DBFs & $0.174(P=0.221)$ & $0.114(P=0.257)$ \\
\hline $\begin{array}{l}\text { TDE versus DBFs } \\
\text { (LT-EJ) }\end{array}$ & $0.290(P=0.333)$ & $0.160(P=0.498)$ \\
\hline TDE versus DBFs $(\mathrm{K})$ & $0.490(P=0.020)$ & $0.314(P=0.043)$ \\
\hline UPDE versus DBCs & $-0.355(P=0.013)$ & $-0.260(P=0.011)$ \\
\hline TDE versus DBCs & $0.427(P=0.002)$ & $0.272(P=0.008)$ \\
\hline $\begin{array}{l}\text { TDE versus DBCs } \\
\text { (LT-EJ) }\end{array}$ & $0.636(P=0.018)$ & $0.470(P=0.036)$ \\
\hline TDE versus DBCs $(\mathrm{K})$ & $0.663(P<0.001)$ & $0.491(P<0.001)$ \\
\hline $\begin{array}{l}\mathrm{TDE}_{\mathrm{WE}} \text { versus } \\
\text { terrestrial rock }\end{array}$ & $0.617(P<0.001)$ & $0.501(P<0.001)$ \\
\hline $\begin{array}{l}\mathrm{TDE}_{\mathrm{WE}} \text { versus marine } \\
\text { rock }\end{array}$ & $-0.555(P<0.001)$ & $-0.445(P<0.001)$ \\
\hline $\mathrm{TDE}_{\mathrm{WE}}$ versus $\mathrm{TDE}$ & $0.119(P=0.381)$ & $0.095(P=0.377)$ \\
\hline TDE & $0.411(P=0.006)$ & $0.332(P=0.005)$ \\
\hline
\end{tabular}

making them broadly comparable. Higher taxic levels (e.g. families) have been demonstrated to be unsuitable proxies for genera in macroevolutionary studies (e.g. Rhodes \& Thayer, 1991; Smith, 1994; Barrett \& Upchurch, 2005; Tarver, Braddy \& Benton, 2007) and were not examined here. Analyses have thus been implemented at the generic level: because it was conducted at the specific level, the supertree of Lloyd et al. (2008) is the exception. In this supertree, a number of species belonging to individual genera were recovered as paraphyletic (e.g. Haplocanthosaurus and Brachiosaurus); therefore each species included in the supertree is considered a unique taxon for the purposes of this study. For phylogenetic diversity curves, the taxa used are restricted to those genera incorporated into the original analyses; however, the taxic diversity curve incorporates all valid sauropodomorph taxa. As a result, the taxic diversity estimate (TDE) incorporates almost twice as many taxa as that of the largest phylogenetic diversity estimate (PDE). This is a consequence partly of the description of numerous taxa since the publication of these phylogenies, but also pertains to the large amount of missing data in taxa represented by very incomplete (or poorly described) specimens that cannot be incorporated into large-scale phylogenetic analyses. However, to attempt to remove any bias, we also compare pruned versions of the TDE with the PDE. This is implemented by restricting the TDE in these comparisons to just those taxa present in the phylogenetic analysis.

\section{(d) Geological age of taxa}

One of the most serious issues with constructing diversity curves is that the geological ages of taxa often cannot be 
Table 4. Results of statistical analyses comparing observed and 'corrected' diversity with sea level. See Table 1 for an explanation of the abbreviations of diversity curves and proxies and Table 2 for other abbreviations. Haq = Haq et al. (1987), Miller $=$ Miller et al. (2005). Statistically significant results are in bold

\begin{tabular}{|c|c|c|}
\hline Comparison & Spearman's rs & Kendall's tau \\
\hline $\begin{array}{l}\text { TDE versus Haq sea } \\
\text { level }\end{array}$ & $0.219(P=0.113)$ & $0.147(P=0.138)$ \\
\hline $\begin{array}{l}\text { TDE versus Haq sea } \\
\text { level }(J)\end{array}$ & $0.221(P=0.340)$ & $0.152(P=0.374)$ \\
\hline $\begin{array}{l}\text { TDE versus Haq sea } \\
\text { level }(\mathrm{K})\end{array}$ & $0.424(P=0.037)$ & $0.313(P=0.039)$ \\
\hline $\begin{array}{l}\text { TDE versus Haq sea } \\
\text { level (EK) }\end{array}$ & $0.818(P=0.001)$ & $0.667(P=0.001)$ \\
\hline $\begin{array}{l}\text { TDE versus Haq sea } \\
\text { level (LK) }\end{array}$ & $-0.375(P=0.220)$ & $-0.222(P=0.367)$ \\
\hline $\begin{array}{l}\text { TDE versus Miller sea } \\
\text { level (LK) }\end{array}$ & $0.312(P=0.327)$ & $0.159(P=0.552)$ \\
\hline $\begin{array}{l}\text { UPDE versus Haq sea } \\
\text { level }\end{array}$ & $-0.561(P<0.001)$ & $-0.397(P<0.001)$ \\
\hline $\begin{array}{l}\text { UPDE versus Haq sea } \\
\text { level }(\mathrm{J})\end{array}$ & $0.479(P=0.023)$ & $0.381(P=0.011)$ \\
\hline $\begin{array}{l}\text { UPDE versus Haq sea } \\
\text { level }(\mathrm{K})\end{array}$ & $-0.657(P<0.001)$ & $-0.549(P<0.001)$ \\
\hline $\begin{array}{l}\text { UPDE versus Haq sea } \\
\text { level (EK) }\end{array}$ & $-0.939(P<0.001)$ & $-0.854(P<0.001)$ \\
\hline $\begin{array}{l}\text { UPDE versus Haq sea } \\
\text { level (LK) }\end{array}$ & $0.015(P=0.962)$ & $0.036(P=0.940)$ \\
\hline $\begin{array}{l}\text { Haq versus Miller sea } \\
\text { level (LK) }\end{array}$ & $0.063(P=0.854)$ & $0.030(P=0.941)$ \\
\hline $\begin{array}{l}\text { Residual DBCs versus } \\
\text { Haq }\end{array}$ & $-0.394(P=0.003)$ & $-0.227(P=0.002)$ \\
\hline $\begin{array}{l}\text { Residual DBCs versus } \\
\text { Haq }(\mathrm{J})\end{array}$ & $0.088(P=0.698)$ & $0.078(P=0.638)$ \\
\hline $\begin{array}{l}\text { Residual DBCs versus } \\
\quad \operatorname{Haq}(\mathrm{K})\end{array}$ & $0.472(P=0.032)$ & $0.326(P=0.030)$ \\
\hline $\begin{array}{l}\text { Residual DBCs versus } \\
\text { Haq (EK) }\end{array}$ & $0.629(P=0.025)$ & $0.394(P=0.083)$ \\
\hline $\begin{array}{l}\text { Residual DBCs versus } \\
\text { Haq (LK) }\end{array}$ & $0.371(P=0.258)$ & $0.333(P=0.172)$ \\
\hline $\begin{array}{l}\text { Residual DBCs versus } \\
\text { Miller (LK) }\end{array}$ & $-0.371(P=0.228)$ & $-0.212(P=0.384)$ \\
\hline $\begin{array}{l}\text { Residual DBFs versus } \\
\text { Haq }(\mathrm{K})\end{array}$ & $0.453(P=0.026)$ & $0.326(P=0.025)$ \\
\hline $\begin{array}{l}\text { Residual DBFs versus } \\
\text { Haq (EK) }\end{array}$ & $0.790(P=0.006)$ & $0.606(P=0.010)$ \\
\hline $\begin{array}{l}\text { Residual DBFs versus } \\
\text { Haq (LK) }\end{array}$ & $-0.259(P=0.407)$ & $-0.091(P=0.728)$ \\
\hline $\begin{array}{l}\text { Residual DBFs versus } \\
\text { Miller (LK) }\end{array}$ & $-0.133(P=0.665)$ & $-0.152(P=0.523)$ \\
\hline
\end{tabular}

constrained with precision. Few fossil taxa can be directly dated (e.g. by radiometric dating), and even when they can the dates obtained are usually restricted to the horizons above and/or below the fossil-bearing layer. Most vertebrate fossils are dated using indirect methods, such as biostratigraphy, which tend to be limited in resolution to the stage level (e.g. Campanian; 83.5-70.6 Myr), or even coarser time bins, and can impose some circularity depending on the taxa involved. For the Mesozoic, stage intervals vary in temporal range from approximately 3 to $13 \mathrm{Myr}$ in duration (Gradstein et al., 2005); thus, any fossil indirectly dated will have an associated error in its temporal range. Many sauropodomorph fossils cannot be dated more accurately than to the epoch level (e.g. Middle Jurassic), with an animal dated as Early Cretaceous confined only to a $46 \mathrm{Myr}$ period. For example, estimates for the age of the Chinese somphospondyl Euhelopus (see Fig. 1) span a $39 \mathrm{Myr}$ interval from the Tithonian through to the Aptian (150.8-112.0 Myr; Wilson \& Upchurch, 2009).

As long as error is randomly distributed, it can only degrade a genuine signal: it cannot create an artificial one (Raup, 1991; Smith, 2001). Previous workers (e.g. Sepkoski, 1993; Adrain \& Westrop, 2000) have demonstrated that stratigraphical and taxonomic revisions have had little significant effect on overall diversity patterns. Thus, although the most recent literature has been used as the basis for our stratigraphic ranges and taxonomy, we do not expect the overall observed diversity curve to differ greatly from those of previous studies. In most instances we use the full suggested temporal span of a taxon, although in some cases we utilise estimates based on more accurate dating techniques. A full list of stratigraphic ranges is included with the list of taxa in the online Appendix.

\section{(3) Preservational biases and sampling quality}

Taphonomic and sampling biases have the potential to affect greatly observed generic richness in the fossil record, and thus the accurate reconstruction of diversity curves for fossil taxa (e.g. Behrensmeyer, Kidwell \& Gastaldo, 2000; Miller, 2000; Alroy et al., 2001, 2008; Upchurch \& Barrett, 2005; Smith, 2007; Smith \& McGowan, 2007; Uhen \& Pyenson, 2007; Peters, 2008; Barrett et al., 2009; Butler et al., 2009c; Wall, Ivany \& Wilkinson, 2009; Benson et al., 2010). Following the work of Raup (1972), numerous investigators have demonstrated that both the amount of rock outcrop and the environments preserved therein have varied throughout geological time (e.g. Ronov et al., 1980; Schindel, 1980; Sadler, 1981; Kalmar \& Currie, 2010). For example, the ratio of terrestrial to marine environments at any time interval is dependent upon sea level (Smith \& McGowan, 2007). As a consequence of this, diversity might simply mirror the amount of rock outcrop and the number of opportunities to observe fossils (NOOs: Raup, 1972, 1976; Alroy et al., 2001; Peters \& Foote, 2001, 2002; Smith, 2001; Smith, Gale \& Monks, 2001; Crampton et al., 2003; Peters, 2005, 2008; Smith \& McGowan, 2005, 2007; Upchurch \& Barrett, 2005; Uhen \& Pyenson, 2007; Fröbisch, 2008; McGowan \& Smith, 2008; Barrett et al., 2009; Butler et al., 2009c; Marx, 2009; Benson et al., 2010). Thus, apparent diversity cannot be entirely controlled by rock outcrop or the NOOs if it is to reflect genuine evolutionary patterns. Therefore, we consider a range of sampling proxies in our comparisons with sauropodomorph diversity, in an attempt to tease apart any genuine biological signal from that of the rock record. 


\section{(a) Rock outcrop}

Upchurch \& Barrett (2005) and Barrett et al. (2009) utilised dinosaur-bearing formations (DBFs) as a proxy for rock outcrop (based on data from Weishampel et al., 2004a), plotting the number of DBFs through time. These authors chose to use DBFs rather than sauropodomorph-bearing formations (as utilised by Hunt et al., 1994) because if a rock unit is capable of preserving large terrestrial vertebrates (i.e. any dinosaur) then it should also be capable of preserving sauropodomorphs; i.e. rock units lacking (or with low diversities of) sauropodomorphs, but preserving other dinosaurs, may reflect genuine situations where sauropodomorph diversity was depauperate. Thus, here we also use $\mathrm{DBF}_{\mathrm{s}}$ for our updated diversity analyses.

A more refined version of using DBFs is to quantify the rock record itself. Peters \& Foote (2001) estimated the amount of marine sedimentary rock outcrop at epoch level for the Phanerozoic of the USA and noted that fluctuations are positively correlated with generic marine diversity. Wall et al. (2009) also recovered a strong correlation between epochlevel Phanerozoic marine diversity and global rock outcrop, albeit through implementing a much coarser global estimate. A global correlation was also noted between the amount of terrestrial sediment (at epoch level) and continental fossil richness (Kalmar \& Currie, 2010). Similarly, Smith \& McGowan (2007) calculated outcrop area of marine and terrestrial sediments at stage level for the Phanerozoic of western Europe. They found that the size and timing of two of the five major Phanerozoic mass extinctions are strongly predicted by rock outcrop but concluded that overall diversity trends (as well as the $\mathrm{K} / \mathrm{P}$ extinction event) were not the result of rock area bias. For the purposes of this study, we utilise the terrestrial and marine rock record data of Smith \& McGowan (2007) to construct Mesozoic rock outcrop curves. We then compare this with the diversity curves produced for Sauropodomorpha (TDE and PDE), as well as taxic diversity from western Europe alone (TDE $\mathrm{WE}_{\mathrm{W}}$ ) in an attempt to clarify whether this region provides a suitable proxy for the global rock record (at least for sauropodomorphs).

\section{(b) Collecting effort}

As well as geological biases (see above), additional human biases exist in terms of taxonomic artefacts (Uhen \& Pyenson, 2007; Alroy et al., 2008; Peters, 2008) and the disproportionate sampling and study of different time intervals (e.g. the Campanian-Maastrichtian has received considerably more attention than most other Mesozoic stages). McGowan \& Smith (2008) also highlighted the likelihood of the global Phanerozoic diversity curve being disproportionately influenced by European and North American fossil data.

Collection-based methods have been used by previous authors in attempts to investigate the diversity of numerous groups (e.g. Crampton et al., 2003; Uhen \& Pyenson, 2007; Alroy et al., 2008; Carrano, 2008a). Thus, in addition to utilising DBFs and rock outcrop, we compare diversity with the number of dinosaur-bearing collections (DBCs) per unit time, derived from the Paleobiology Database (www.pbdb.org; Carrano, 2008b). These collections represent discrete, independent samples of dinosaurs from specific geographic and stratigraphic localities; they have been as finely resolved as the published record allows.

An additional way to assess collecting effort is to construct collector curves for fossil taxa by plotting the cumulative number of newly described taxa against the date of description. When the rate of new discoveries declines markedly, it is assumed that true diversity (at least in terms of those taxa that were fossilised and thus had a chance of being discovered) has been approached (Benton, 1998). The nearcomplete collector curve should thus have a sigmoid shape with a slow initial rise followed by a phase of rapid increase, before levelling off towards an asymptote (Benton, 1998, 2008). Another method is to look for correlations between the geological ages of taxa and their years of description. If we were increasingly driving back (or forward) the age of the oldest (or youngest) taxon, then we might suspect that there were large gaps in our sampling (Benton, 1998; Fountaine et al., 2005). If, at the other end of the spectrum, the fossil record was extremely well sampled then we might expect new discoveries to be from geological ages from which we already have numerous taxa. A more likely scenario is that new discoveries from an overall well-sampled fossil record will fill in the various internal stratigraphic gaps within that record. Here we utilise both of these measures to assess further the contribution of human error in estimating diversity.

\section{(c) Residuals}

The effect of sampling biases on diversity can also be analysed by constructing a model in which sampling opportunity perfectly predicts the TDE, then subtracting this from the TDE, leaving a residual 'unexplained diversity signal' (Smith \& McGowan, 2007; Barrett et al., 2009; Butler et al., 2009c; Benson et al., 2010). These models have been constructed by independently sorting log sampling bias (e.g. DBFs and DBCs) and log TDE from low to high values, then fitting a linear model of the form $y=m x+c$ to the ordered data, where $x$ is the sampling proxy datum, $m$ is the gradient of the line and $c$ is a constant.

We apply this equation to the sampling bias data in its original order (i.e. plotted against geological time) to derive a temporal series of modelled (or predicted) diversity (MDE). Lastly, we subtract MDE from TDE to obtain the residual, which therefore represents fluctuations in diversity that cannot be explained in terms of the sampling bias (Smith \& McGowan, 2007; Barrett et al., 2009; Butler et al., 2009c; Benson et al., 2010). We then repeat this last step, replacing TDE with PDE (Barrett et al., 2009), to obtain residuals of PDE from MDE. Using this residuals-based method, we then compare TDE and PDE with the sampling biases outlined in the preceding sections. Time periods in which residuals vary between different sampling biases could help in identifying which factors affect particular temporal intervals. 


\section{(d) Rarefaction}

One of the fundamental problems with diversity analyses is their dependence on sample size (Sanders, 1968; Raup, 1975; Colwell \& Coddington, 1994). To overcome this problem, Sanders (1968) developed the method of rarefaction (later built upon and discussed further by: Hurlbert, 1971; Simberloff, 1972; Heck, Van Belle \& Simberloff, 1975; Raup, 1975; Tipper, 1979; Gotelli \& Colwell, 2001; Hammer \& Harper, 2006) to compare taxonomic richness in samples of different sizes and to investigate the effect that sample size has upon taxon counts (Hammer \& Harper, 2006).

Rarefaction has been used to address a wide range of problems in palaeobiology, including: the effects of sample size on diversity (e.g. Miller \& Foote, 1996), estimates of taxonomic richness (e.g. Fastovsky et al., 2004) and abundance (e.g. Davis \& Pyenson, 2007); morphological variety (Foote, 1992); comparisons of diversity between biofacies and sea-level changes (e.g. Westrop \& Adrain, 1998); and fluctuations in diversity at extinction and radiation events (e.g. Adrain et al., 2000).

Nearly all analyses of dinosaur diversity have been limited to counts of numbers of taxa or lineages per stage. Thus far, only one published study (Fastovsky et al., 2004) has implemented rarefaction in an attempt to elucidate global dinosaur diversity [although studies by Sheehan et al., (1991) and Pearson et al., (2002) have also used rarefaction to address regional diversity]: Fastovsky et al. (2004) utilised the global dinosaur locality dataset of Weishampel et al. (2004a), pruning it to exclude generically indeterminate material. These authors demonstrated a steady increase in diversity throughout the Mesozoic and argued that dinosaurs were not in decline in the last $10 \mathrm{Myr}$ of the Mesozoic (see also Sheehan et al., 1991; Pearson et al., 2002; Wang \& Dodson, 2006). This study has been criticised by several workers (Archibald, 2005; MacLeod \& Archibald, 2005; Sullivan, 2006), who questioned the interpretation of the rarefied data by Fastovsky et al. (2004) and suggested (after re-analysis) that a Maastrichtian decline in dinosaur diversity is still well supported. However, Carrano (2008a) demonstrated that dinosaur diversity for the latest Cretaceous of North America shows much less variation among formations and time intervals than is documented by stage-level diversity counts and suggested that, rather than reflecting an endCretaceous decline, Campanian-Maastrichtian fluctuations (at least for North America) are the product of ecological, environmental and sampling biases (particularly of an anthropogenic nature).

Following Fastovsky et al. (2004), we omit all generically indeterminate occurrences from our global database. We then split generic occurrences into their respective stratigraphic stages, and count each taxon as present for each interval in which it occurred (see online Appendix). Smaller time bins (i.e. substage) are not used because of constraints on minimum sample sizes for effective rarefaction (Krebs, 1999; Hammer \& Harper, 2006). Sample-based rarefaction (using the number of localities each genus is found at in each stage) is implemented in PAST (Hammer et al., 2001), with only time bins (7) containing 30+ samples rarefied, and curves of rarefied diversity are constructed.

One potential problem with this method of rarefaction is the omission of generically indeterminate occurrences. Previous rarefaction analyses have excluded these and have only included numbers of occurrences of genera. However, in a given sample, it is unlikely that all individuals will be recognised to the level of genus: many sauropodomorph individuals cannot be recognised beyond clade or family level (e.g. Titanosauria). As such, a modified version of the rarefaction analysis is also implemented. For each locality, an additional genus is included for material representing any clade that cannot include any of the named genera. For example, if a site contains remains of Dicraeosaurus, as well as indeterminate diplodocid and diplodocoid elements, then its total generic diversity would be two because the indeterminate diplodocid materials cannot be referred to Dicraeosaurus (a dicraeosaurid diplodocoid; see Fig. 1) and must belong to a second taxon. However, the indeterminate diplodocoid could represent undiagnostic materials of either form and is thus not counted. The same procedure is applied when only indeterminate materials are present (i.e. two genera are considered present in a quarry that preserves indeterminate dicraeosaurid, diplodocid and diplodocoid materials). These indeterminate occurrences are summed and considered additional genera for each time bin. As well as enabling the inclusion of indeterminate materials and thereby attempting to assess 'cryptic' diversity, our method also has the advantage of greatly increasing the sample size for each time bin, which has obvious benefits for rarefaction (i.e. increasing the size of the smallest sample). Sample-based rarefaction, using 'all occurrences', is implemented at several different minimum sample sizes: 30 (22 stages included), 50 (18 stages), 70 (11 stages) and 90 (7 stages). Lastly, to test previous suggestions of a latestCretaceous diversity decline, we implement substage-level 'all occurrences' rarefaction for the Campanian-Maastrichtian, using the early ( sample size $=64)$ and late ( sample size $=83$ ) Campanian as our smallest sample sizes.

One issue concerns the choice of time bins, as stages vary in duration. Rarefaction is time dependent, so we would expect to sample more taxa during longer time periods; thus, it is perhaps best to use time bins of approximately equal duration (Raup, 1975; Alroy et al., 2001, 2008). We might expect that more genera were present during longer time intervals than short ones, even when both had similar levels of diversity at any one point in time. Additionally, there may be a higher chance of genera being preserved given a longer time period. For example, the Early Cretaceous is $45.9 \mathrm{Myr}$ while the Late Jurassic is only 15.7 Myr in duration. Similarly, the Campanian represents a time interval of 12.9 Myr while the Hettangian is only 3.1 Myr in duration. However, when TDE and length of stage and epoch are compared, we find no statistically significant correlations $(P>0.3$ for all tests). In addition, there is no correlation between time bin duration and number of samples $(P>0.1$ for all tests). Consequently, our choice of time bins seems adequate for these analyses. 


\section{(4) Comparisons with sea level}

Closely related to the rock record is the record of fluctuating sea levels (Haq, Hardenbol \& Vail, 1987). It has long been noted that eustatic Phanerozoic sea-level fluctuations coincide with many episodes of variation in marine diversity (Newell, 1952; Johnson, 1974; Hallam, 1989; Smith, 2001). Other workers have also observed a close correlation between patterns of sauropodomorph (and/or dinosaur) diversity and sea-level fluctuations (Haubold, 1990; Hunt et al., 1994; Upchurch \& Barrett, 2005). Although sauropodomorphs were terrestrial, sea level could have affected their apparent diversity abiotically, e.g. through controlling their preservation potential (Upchurch \& Barrett, 2005). The remains of terrestrial organisms may be more likely to reach aquatic environments during periods of high sea level, meaning they are more likely to be preserved (Haubold, 1990). Additionally, coastal and marginal marine environments potentially stand a better chance of being preserved during transgressive phases (A. B. Smith, personal communication 2009). If correct, high sea level should be correlated with high observed diversity (assuming that genuine diversity fluctuations do not obscure the effects of variations in preservation rates). The opposite effect has also been proposed: the available land area on which to preserve a terrestrial record could be greatly reduced during times of high sea level, resulting in a poorer fossil record (Markwick, 1998). Other workers have proposed biotic factors that might cause sea level to be positively or negatively correlated with genuine diversity. For example, in terrestrial animals, allopatric speciation is likely to happen during high sea levels as land areas become separated, whereas during low sea levels there may be mixing of previously isolated organisms, potentially resulting in extinctions (Bakker, 1977; Horner, 1983; Weishampel \& Horner, 1987). Conversely, the formation of geographic barriers may also result in extinction events as the sizes of some habitats dwindle (Dodson, 1990; Upchurch \& Barrett, 2005).

The current study replicates earlier analyses by comparing both observed (TDE) and 'corrected' sauropodomorph diversity (i.e. PDE, residuals and rarefaction) with the sealevel curve of Haq et al. (1987). By using both observed and 'corrected' diversity, we can attempt to tease apart biotic and abiotic effects of sea level on diversity. In addition, we implement a finer scale study to look for correlations solely during the Late Cretaceous, utilising a recently developed backstripped sea-level curve (Miller et al., 2005), which represents the global sea-level record for the past $100 \mathrm{Myr}$. For both sea-level curves, average sea level is calculated for each substage time bin. It should be noted, however, that the stratigraphy of Haq et al. (1987) differs considerably from the recent Gradstein et al. (2005) timescale. For example, the Oxfordian is dated as 145-152 Ma in the former and 155.7-161.2 Ma in the latter, while the Jurassic/Cretaceous boundary is dated at $131 \mathrm{Ma}$ in the Haq et al. (1987) study but is now dated at 145.5 Ma (Gradstein et al. 2005). Thus, the re-calibrated Mesozoic sea-level data of Haq et al. (1987) [as listed in Miller et al. (2005)] are used here.

\section{(5) 'Summary' diversity}

Lastly, we present a 'summary' diversity curve; this is constructed qualitatively and diversity fluctuations are relative. Peaks and troughs common to all three estimates (PDE, residuals and rarefaction) are considered genuine, and correspondingly when all three indicate the effect of sampling biases then observed diversity is considered an artefact. When our diversity estimates contradict one another, we take an 'average', e.g. if two estimates show peaks but one demonstrates the effect of sampling, then we consider this a small diversity peak. Where this contradiction is more significant (i.e. some estimates show a peak and some show a trough), we illustrate both possible diversity curves.

\section{ANALYSES AND RESULTS}

In this section we outline and present the results of the various analyses implemented, beginning with a description of the updated TDE. The comparisons between the different PDEs are also reported, as are our statistical tests between diversity (both TDE and PDE) and sampling proxies. Lastly, we present the statistical comparisons between our diversity curves and sea level.

\section{(1) Sauropodomorph taxic diversity}

The updated taxic diversity curve (Fig. 5) largely follows previous analyses (Fig. 4; Barrett \& Upchurch, 2005; Upchurch \& Barrett, 2005; Barrett et al., 2009); only two slight differences will be commented on. Firstly, a diversity trough in the Oxfordian was demonstrated by both Upchurch \& Barrett (2005) and Barrett et al. (2009), and the new TDE agrees with this, but indicates that this represents the nadir in sauropodomorph diversity. Secondly, the TDE shows an early Maastrichtian increase in diversity from the Campanian, with the magnitude of this peak close to that of the Kimmeridgian-Tithonian apex. Such a substantial peak has not been reported in previous sauropodomorph diversity analyses [although notable peaks are apparent in Upchurch \& Barrett (2005) and Barrett et al. (2009)] and reflects the large number of taxa named from the latest Cretaceous in recent years (e.g. Maxakalisaurus and Uberabatitan), subsequent to the publication of these earlier diversity analyses.

\section{(2) Statistical comparisons between phylogenetic and taxic diversity}

A diversity curve based on a composite cladogram of Upchurch et al. (2004, 2007) (UPDE) was compared with curves derived from the basal sauropodomorph and sauropod diversity curves of Yates (2007) (YPDE) and Wilson (2002) (WPDE), respectively. Comparisons were also made between UPDE and taxic diversity (TDE), as well as the sauropodomorph element of the supertree of Lloyd et al. (2008) (LPDE), in an attempt to elucidate sauropodomorph diversity. UPDE and TDE were also compared with the 


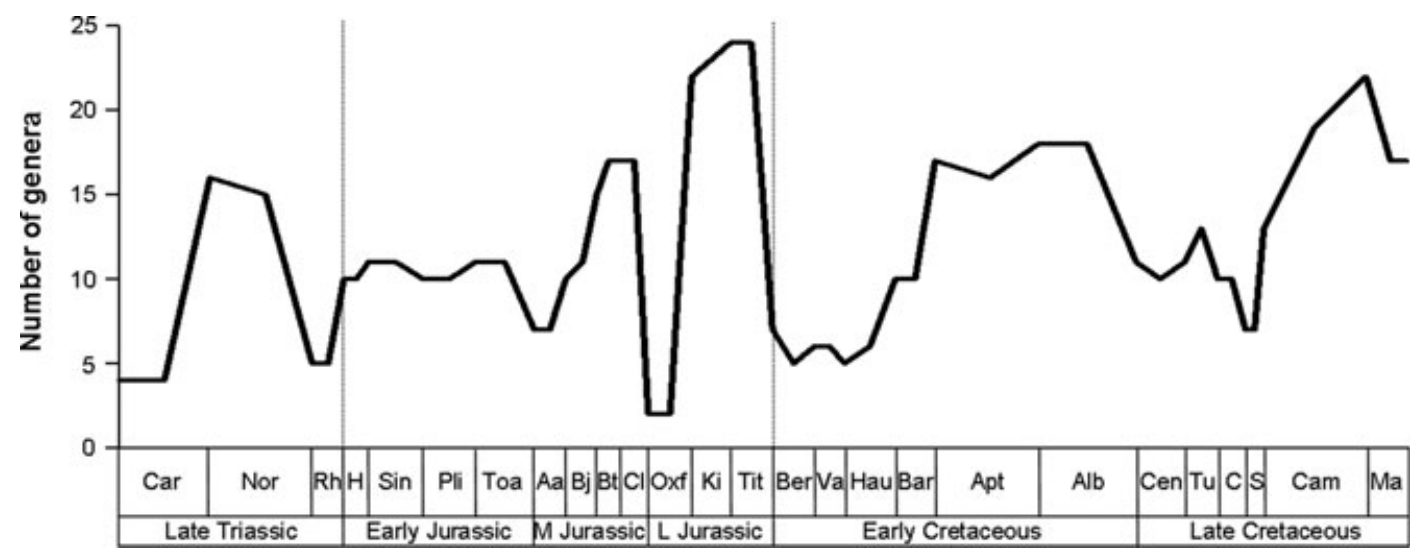

Fig. 5. Updated sauropodomorph taxic diversity estimate (TDE) through the Mesozoic. See Fig. 3 for abbreviations.

diversity curves of Barrett et al. (2009) (BTDE and BPDE). To make statistical comparisons more meaningful, only the basal sauropodomorph element of the UPDE (i.e. Upchurch et al., 2007) was compared with YPDE; similarly, only the sauropod element of the UPDE (i.e. Upchurch et al., 2004) was compared with WPDE. Lastly, the pruned versions of TDE (i.e. the TDE reduced to just those taxa present in the phylogenetic diversity estimates: $\mathrm{TDE}_{\mathrm{P}}$ ) were compared with the UPDE and LPDE (i.e. the phylogenies which sample all sauropodomorphs). Fig. 6 displays the UPDE, LPDE, YPDE and WPDE curves, while Table 2 reports the statistical comparisons.

Overall, UPDE and YPDE are strongly correlated with one another, whereas UPDE and WPDE display a moderately strong correlation (see Table 2). The correlation between UPDE and TDE is considerably weaker, although when restricted to just the Late Triassic-Jurassic, this correlation is extremely strong (while there is no correlation between the two curves for the Cretaceous; Table 2). UPDE and TDE are strongly correlated with BPDE and BTDE, respectively, but show no, or only a very weak, correlation when the phylogenetic and taxic diversity estimates are compared (Table 2). UPDE and TDE show only a weak correlation with LPDE and this disappears when the Cretaceous is examined separately. LPDE does not show any closer correlation when compared to $\mathrm{TDE}_{\mathrm{P}}$; however, UPDE is correlated with TDE even for the Cretaceous (Table 2; $c f$. UPDE versus TDE for the Cretaceous).

\section{(3) Statistical comparisons between diversity and sampling proxies}

UPDE and TDE have been compared with numbers of DBFs and DBCs, as well as western European rock outcrop area (Figs. 7-8). Overall, there is a negative correlation between

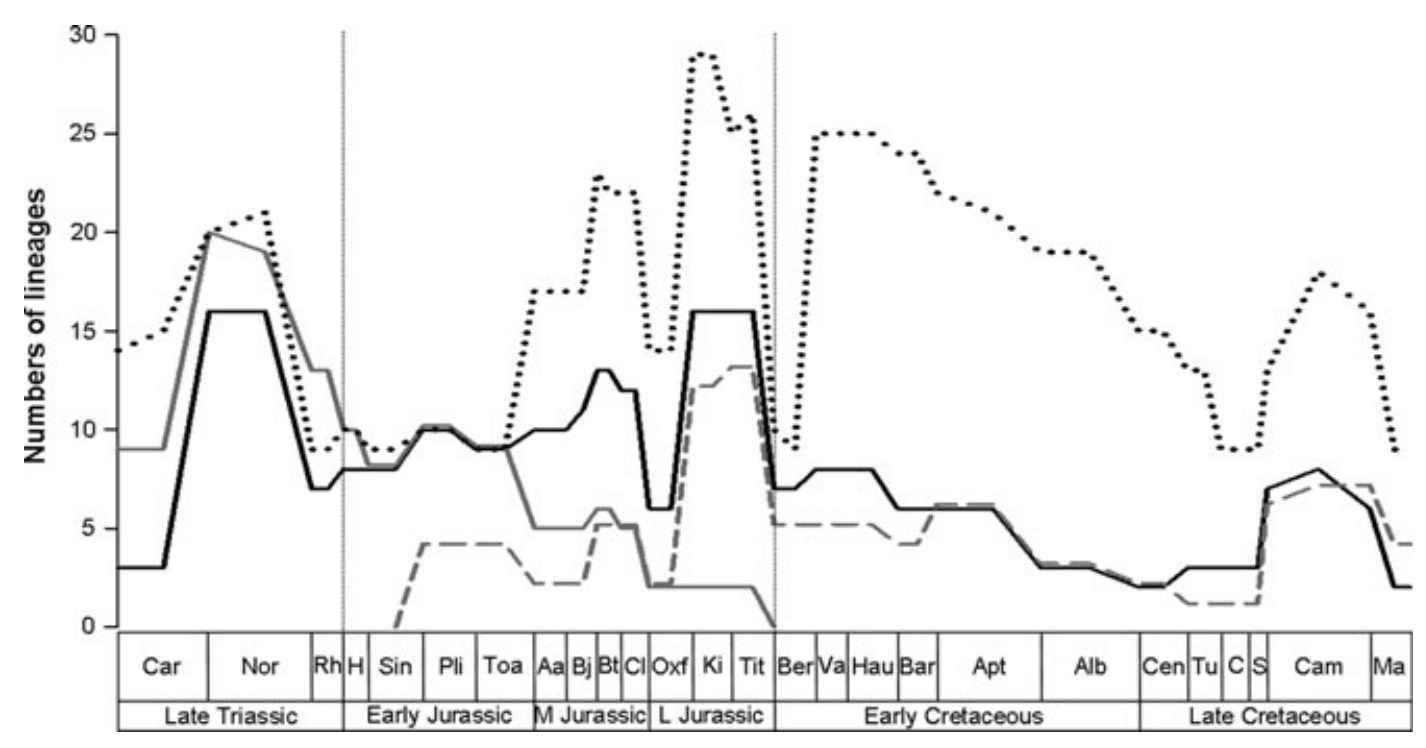

Fig. 6. Sauropodomorph phylogenetic diversity estimates (PDEs) through the Mesozoic. Black solid line = UPDE; grey solid line $=$ YPDE; grey dashed line = WPDE; black dotted line = LPDE. See Table 1 for explanation of the abbreviations for the diversity curves and Fig. 3 for abbreviations of geological stages. 


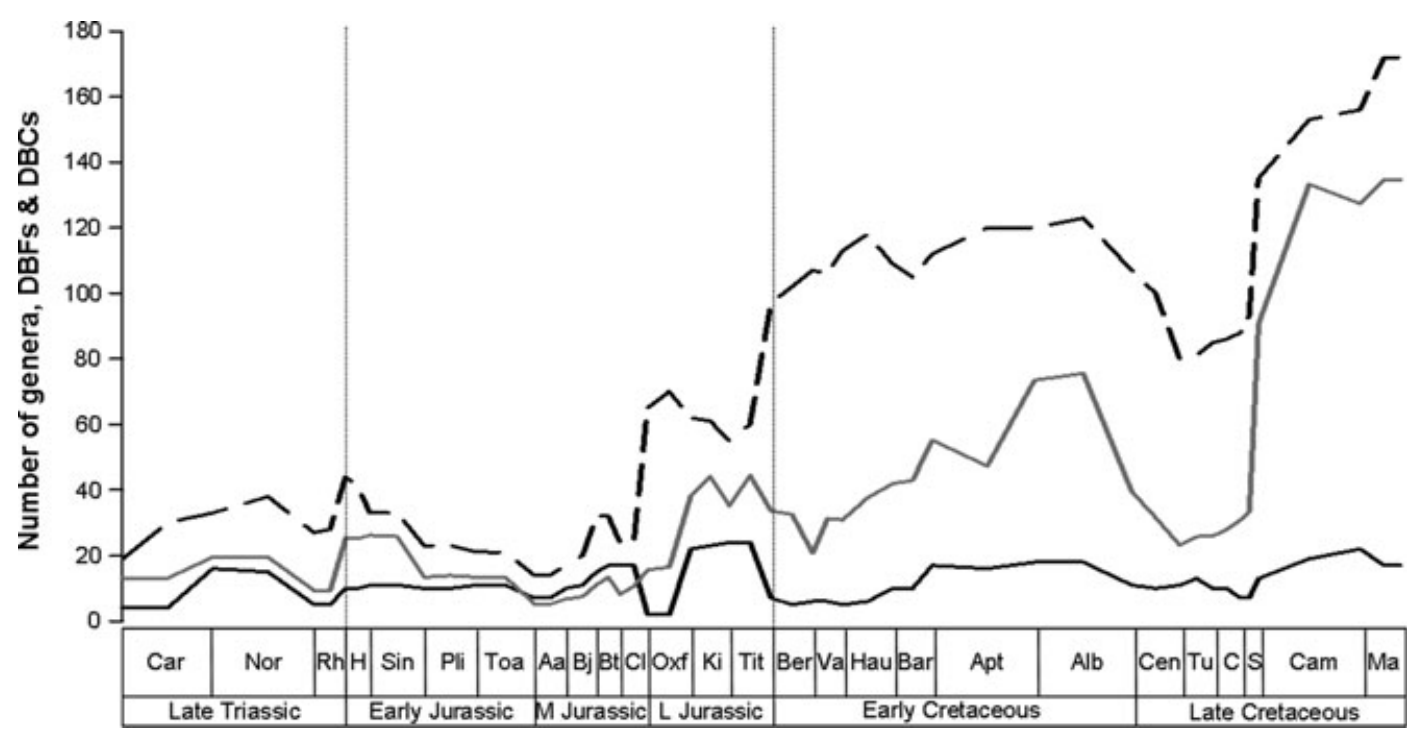

Fig. 7. Taxic diversity estimate (TDE) plotted against numbers of dinosaur-bearing formations (DBFs) and dinosaur-bearing collections (DBCs). Black solid line = TDE; black dashed line = DBFs; grey solid line = DBCs. Note that DBCs have been divided by 10 to allow the curves to be plotted together. See Fig. 3 for abbreviations.

DBFs and the UPDE, but no significant correlation with the TDE (see Table 3). Barrett et al. (2009) also found only a weak correlation between sauropodomorph genus richness and DBFs and commented (p. 2671) that 'the latter measure is an exceptionally poor predictor of sauropodomorph diversity'. There is no correlation between the UPDE and DBFs when we consider smaller time bins (period and epoch), with the exception of a moderately strong, negative correlation in the Early Jurassic (Table 3). The number of DBCs is positively correlated with the TDE for the Mesozoic and has a weakly negative correlation with the UPDE (Table 3).
A correlation exists between DBCs and TDE for the Late Triassic-Early Jurassic, while the TDE (but not the UPDE) shows a significant correlation with both DBFs and DBCs when only the Cretaceous is considered (Table 3).

There is no correlation between either the TDE or UPDE and terrestrial western European rock outcrop area. Furthermore, there is no correlation when diversity and marine rock outcrop are compared (Table 3). However, when only western European taxic diversity (TDEwE) is considered, there is a relatively strong correlation with both terrestrial (positive) and marine (negative) rock area (see

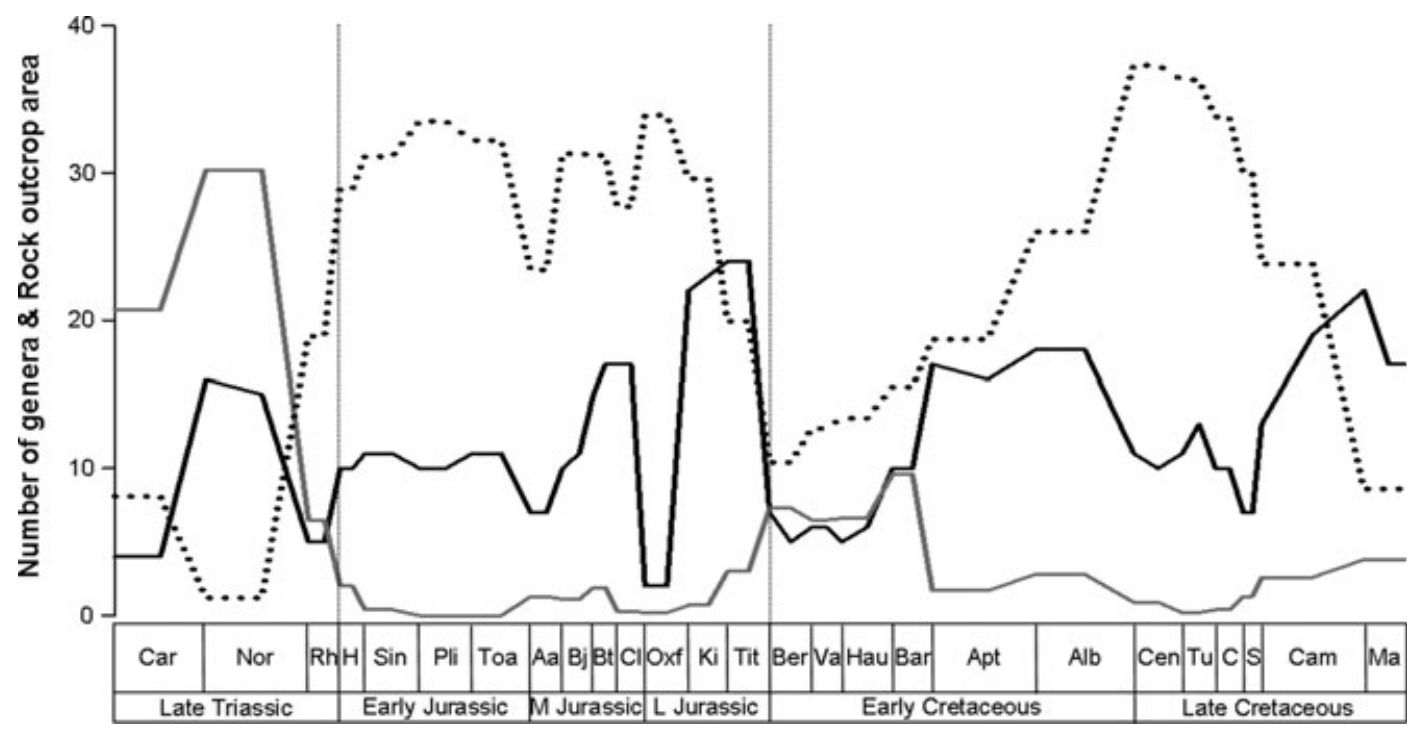

Fig. 8. Taxic diversity estimate (TDE) plotted against terrestrial and marine rock outcrop area (based on numbers of maps with outcrop; Smith \& McGowan, 2007). Black solid line = TDE; grey solid line = terrestrial rock; black dotted line = marine rock. Note that the rock outcrop values have been divided by 10 to allow the curves to be plotted together. See Fig. 3 for abbreviations. 


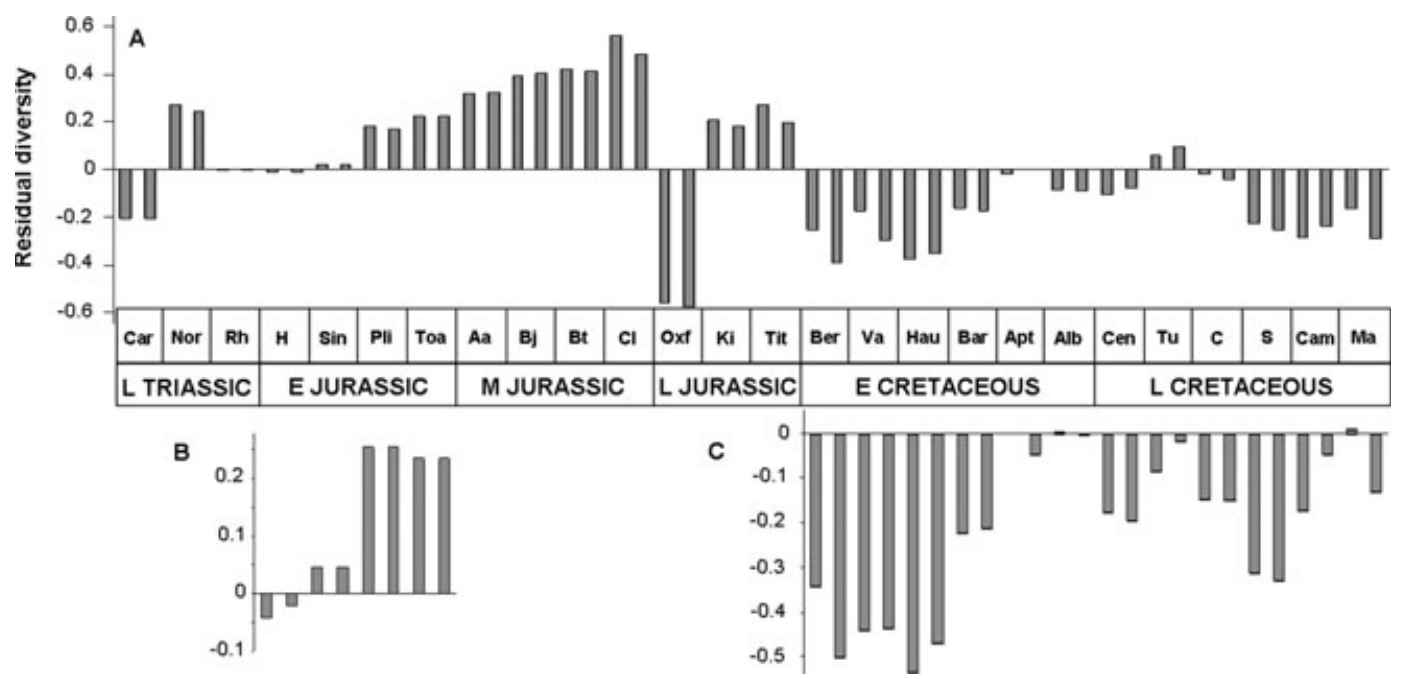

Fig. 9. Residual diversity through time: (A) Taxic diversity estimate (TDE)-based residuals using dinosaur-bearing collections (DBCs) for the Mesozoic; (B) Upchurch et al. (2004, 2007) phylogenetic diversity estimate (UPDE)-based residuals using dinosaur-bearing formations (DBFs) for the Early Jurassic; (C) TDE-based residuals using DBFs for the Cretaceous. See Fig. 3 for abbreviations.

Table 3). TDEWE shows no correlation with global TDE but, slightly surprisingly, is correlated with the UPDE.

\section{(4) Residuals and rarefaction}

As noted in Section II. 3c, residuals were implemented only for those proxies correlated with diversity, and only for the particular time intervals where the correlation occurs. TDE-based residuals were thus constructed for DBCs throughout the Mesozoic, as well as for Cretaceous DBFs (Fig. 9). UPDE-based residuals were constructed only for Early Jurassic DBFs. The residual peaks and troughs are described in Section IV.

Implementation of 'genus-only' rarefaction allows only a few observations to be made regarding fluctuations in diversity, because of sizable error bars (Fig. 10). Similar
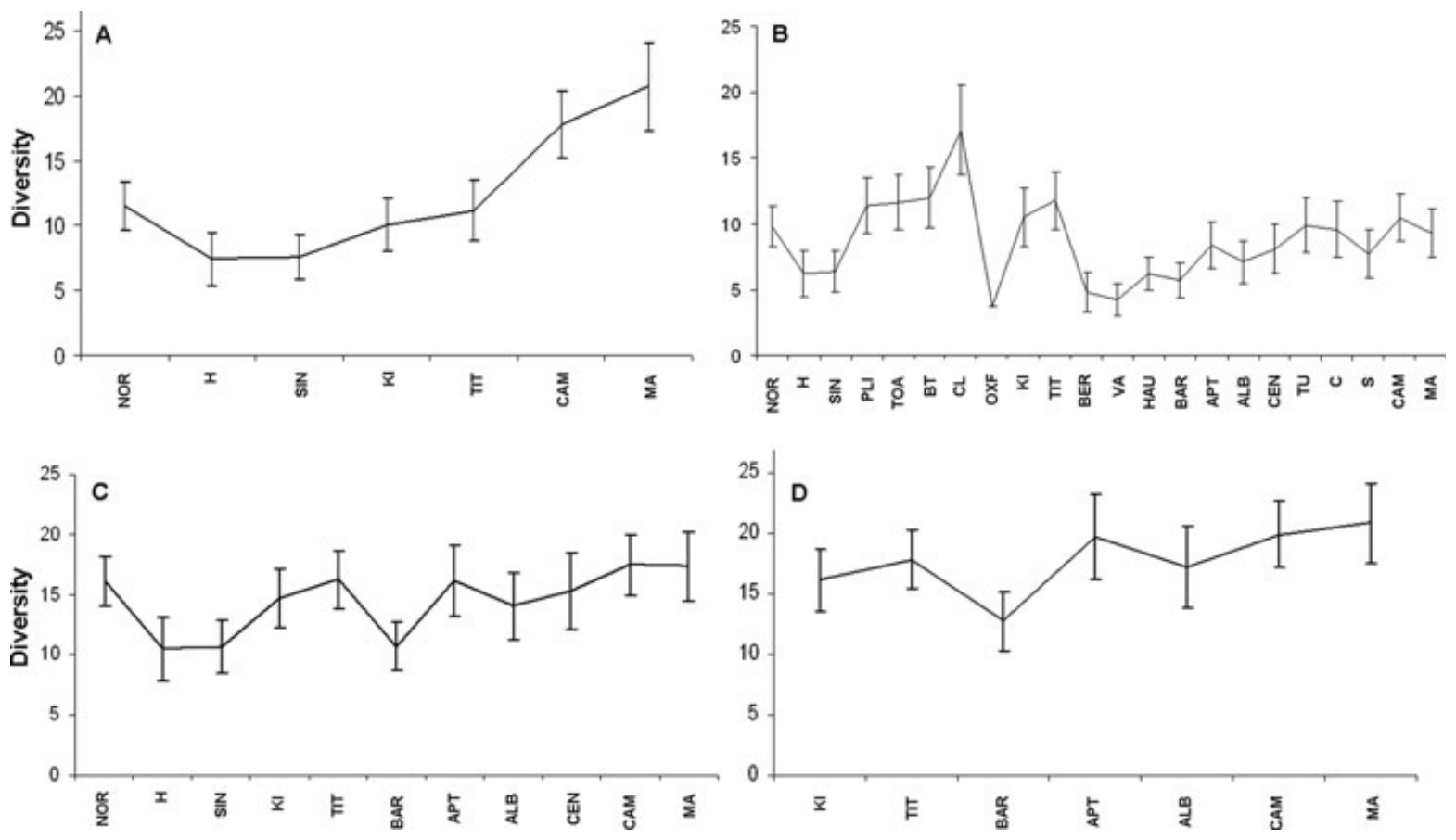

Fig. 10. Rarefied diversity through time: (A) genus-only occurrences (sample size $=30$ ); (B) all-occurrences (sample size $=30$ ); $(\mathrm{C})$ all-occurrences (sample size $=70$ ); (D) all-occurrences ( curve. See Fig. 3 for abbreviations. 
problems affect the 'all-occurrences' rarefaction; however, much more is discernible from these diversity plots (Fig. 10). Those peaks and troughs that can be distinguished are commented upon in Section IV. No fluctuations in diversity could be determined from our substage-level rarefaction for the latest Cretaceous.

\section{(5) Historical collecting effort}

In total, 175 sauropodomorph taxa are considered valid herein (see online Appendix). Their cumulative rate of discovery displays no asymptote and is in the rapid increase phase (see Fig. 4 in Mannion \& Upchurch, $2010 b$ ), suggesting that many more genera remain to be discovered (Benton, 1998; Wang \& Dodson, 2006). New discoveries are not driving back the geological age of the oldest sauropodomorphs [e.g. Thecodontosaurus, from the late Carnian-Rhaetian of the UK, was the first sauropodomorph to be scientifically described (Riley \& Stutchbury, 1836) and still remains one of the oldest known], nor are they extending our knowledge into younger time periods [e.g. Magyarosaurus from the late Maastrichtian of Romania was described by Nopcsa (1915), but no Paleogene sauropods have been recovered subsequently]. However, new discoveries are filling many gaps in the sauropod fossil record, e.g. Bonitasaura and Futalognkosaurus have been named in recent years from the early Late Cretaceous, an interval which previously yielded very little sauropod material.

Of these 175 valid taxa, 50 come from Asia and 46 from South America. 30 taxa have been described from Europe, 25 from Africa, and 21 from North America; just two have been described from Australasia and only one from Antarctica. Three countries account for over half of all sauropodomorph diversity: Argentina (38 taxa), China (36 taxa) and the USA (20 taxa). Over half (101 genera) of sauropodomorph taxa are from Laurasia, with 74 from the approximately equally sized Gondwana (Smith, Smith \& Funnell, 1994). Given their similarity in surface area, this distributional skew almost certainly reflects the Northern Hemisphere origin of dinosaur palaeontology: for example, note that just two Gondwanan taxa were named prior to the 1910s, compared to 20 Laurasian taxa.

\section{(6) Comparisons between sea level and diversity}

The sea level curve of Haq et al. (1987; Fig. 11) was statistically compared with observed (TDE) and 'corrected' diversity; it was also qualitatively compared with 'summary' diversity (see Section IV). Comparisons were also made with the Late Cretaceous element of the Miller et al. (2005) curve.

There is no correlation between the TDE and sea level for the Mesozoic; however, a strong positive correlation is recovered when the Cretaceous and Early Cretaceous are examined separately (Table 4). All other time-slices produce non-significant results.

Sea level is positively correlated with the UPDE for the Jurassic and strongly negatively correlated when the Early Cretaceous is examined. However, there is no correlation between diversity and sea level when comparisons are limited to the Late Triassic-Early Jurassic or Late Cretaceous time intervals.

There is only a weak negative correlation between DBC-based residuals and sea level for the Mesozoic (Table 4). There is no correlation when we compare the two for the Jurassic or Late Cretaceous separately, but there is a statistically significant positive correlation between

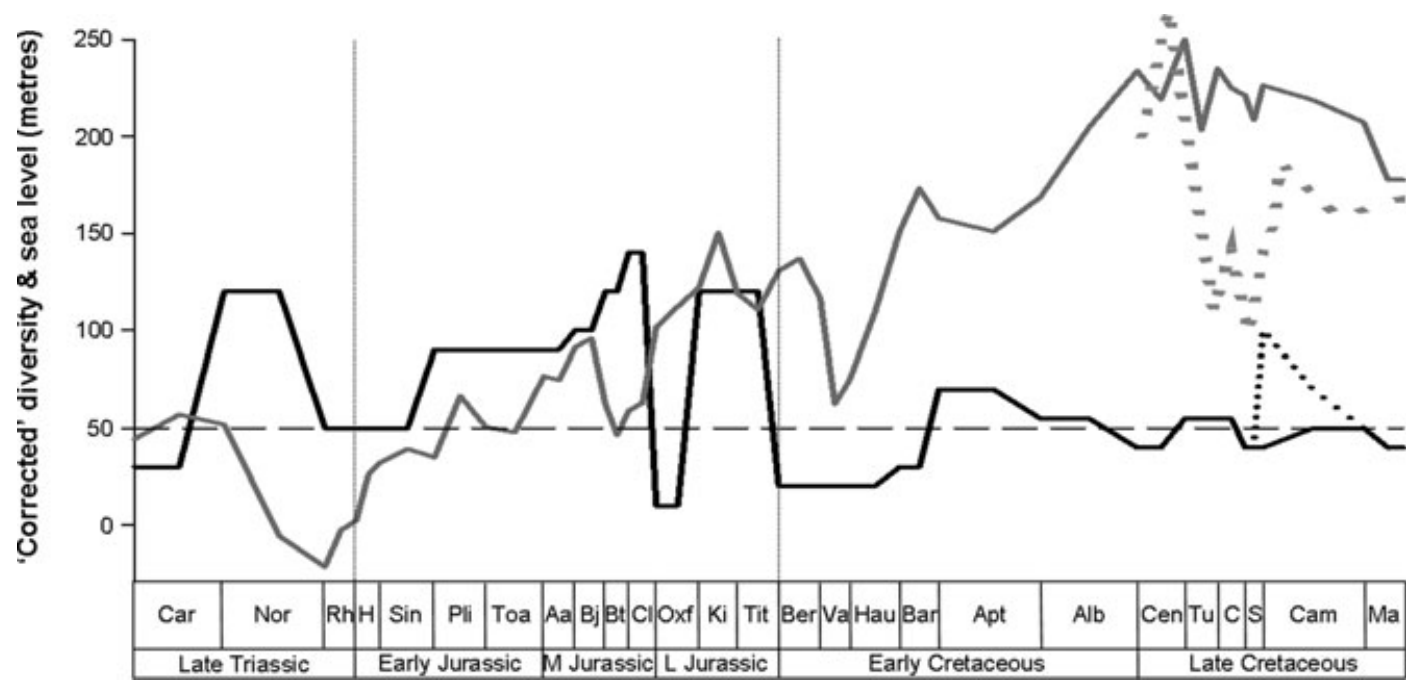

Fig. 11. 'Summary' diversity plotted against sea level (Haq et al., 1987; Miller et al. 2005). Black solid line = 'summary' diversity; black dotted line = alternative Campanian-Maastrichtian 'summary' diversity; grey solid line = Haq et al. (1987) sea level; grey dotted line = Miller et al. (2005) sea level; black dashed (horizontal) line = sampling biases. Note that the $y$-axis values are for sea level only; 'summary' diversity only shows relative fluctuations in diversity (see text for explanation of construction). Note that the Miller et al. (2005) sea level values have been multiplied by 3 to allow the two sea level curves to be plotted together. See Fig. 3 for abbreviations. 
DBC-based residuals and sea level in the Early Cretaceous (Table 4). A moderately strong positive correlation between DBF-based residuals and sea level is recorded for the Cretaceous (Table 4). This correlation disappears when we examine the Late Cretaceous by itself, but is greatly reinforced when only the Early Cretaceous is considered (Table 4).

As a consequence of the rarefied datasets excluding various stages because of sample sizes, a meaningful statistical comparison with sea level cannot be implemented. However, comparison of the individual peaks and troughs are included in Section IV.

\section{DISGUSSION}

\section{(1) 'Summary' diversity through time}

\section{(a) Late Triassic}

The UPDE and YPDE both show an initial increase in diversity from the Carnian (228.0-216.5 Myr) to a peak in the Norian (216.5-203.6 Myr), before a steep decline in the Rhaetian (203.6-199.6 Myr; Fig. 6). This pattern was also noted by Barrett \& Upchurch (2005) and Barrett et al. (2009). However, consideration of residuals suggests that genus richness was low in the Carnian, whereas diversity in the Rhaetian appears to be partly controlled by sampling biases. These results contrast with previous suggestions that the late Norian/Rhaetian (203.6 Myr) represents one of the major Phanerozoic extinction events (see Bambach, 2006, and references therein; Arens \& West, 2008), although this extinction has mostly been associated with marine faunas [Benton, 1994; but see Benson et al. (2010) for a conflicting result regarding marine reptiles]. Diversity in the Norian does appear to be genuinely high (Figs 9-11), reflecting the diversification of 'prosauropods' and basal sauropodomorphs.

\section{(b) Early Jurassic}

The UPDE shows a slight increase in diversity from the Rhaetian (but less than the Norian peak), whereas the YPDE shows a continued decline (Fig. 6). The WPDE and BPDE also show a Hettangian (199.6-196.5 Myr) increase in genus richness. Following this increase, the UPDE curve remains relatively flat, whereas the YPDE continues to decline until a diversity increase in the Pliensbachian (189.6-183.0 Myr; Fig. 6). Barrett et al. (2009) demonstrated a similar diversity plateau as in the UPDE but differed in showing a notable Toarcian (183.0-175.6 Myr) decline. Residuals and rarefaction indicate that diversity in the Hettangian-Sinemurian is controlled by sampling, whereas the Pliensbachian-Toarcian peak appears genuine (Figs 9-11), perhaps reflecting the onset of eusauropod diversification. There is no evidence for a late Pliensbachian-early Toarcian extinction event, in contrast to that among marine taxa (Harries \& Little, 1999; Bambach, 2006; Arens \& West, 2008).

\section{(c) Middle Furassic}

Although the YPDE and WPDE both show a steep drop in diversity in the Aalenian (175.6-171.6 Myr) (by which point non-eusauropod sauropodomorphs were replaced by eusauropods: Barrett \& Upchurch, 2005), UPDE shows diversity levels comparable to the Toarcian (Fig. 6). Although the extinction of basal forms explains why the YPDE drops at this point, this factor cannot explain the differences between the other two curves; this peak in the UPDE can be explained by the inclusion of Bellusaurus, which is discussed in Section IV. 2. Following this, the UPDE and WPDE both show an increase in diversity, and all measures indicate a peak in the Bathonian-Callovian (167.7-161.2 Myr; Figs 6, 11), reflecting the neosauropod radiation (although residuals indicate a diversity peak throughout the Middle Jurassic; Figs 9, 10).

\section{(d) Late Furassic}

All measures recover a severe decline in diversity in the Oxfordian (161.2-155.7 Myr; Upchurch \& Barrett, 2005; Barrett etal., 2009), followed by a peak in the Kimmeridgian-Tithonian (155.7-145.5 Myr). Thus, it appears that the Oxfordian was a genuine time of depauperate diversity (Upchurch \& Barrett, 2005) (although see Section IV. 4), whereas the Kimmeridgian-Tithonian diversity peak seems to represent a real biological event (Figs. 9-11), and is not an artefact of sampling.

\section{(e) Early Cretaceous}

All measures show a large drop in diversity at the $\mathrm{J} / \mathrm{K}$ boundary (145.5 Myr), with taxon richness remaining low at least until the Barremian (130.0-125.0 Myr; Fig. 6). Wagner (2000a) has argued that PDEs should be conservative in detecting mass extinctions, as a consequence of the backward smearing of origination times which diminish the scale of the mass extinction (note that this can only occur if some lineages survive: if the whole group goes extinct, then there are no lineages left to 'backsmear'). This would suggest that the $\mathrm{J} / \mathrm{K}$ event potentially represents a genuine extinction (Upchurch \& Barrett, 2005; Barrett et al., 2009). However, the UPDE and WPDE show a relatively high percentage of ghost lineages in the earliest Cretaceous [in particular the Berriasian (145.5-140.2 Myr): five ghost lineages compared to two actual fossil occurrences (UPDE)]. The increased 'gappiness' in the fossil record immediately after mass extinctions has been shown to reflect taphonomic bias (Twitchett, Wignall \& Benton, 2000), as Lazarus taxa that temporarily disappear tend to be found in environments that also temporarily disappear (Smith et al., 2001). Thus, this Berriasian 'gappiness' may result from lack of preservation of the environments, rather than fluctuations in taxon abundances (Smith, 2001). However, support for a 
$\mathrm{J} / \mathrm{K}$ extinction event from the residuals and rarefaction analyses indicates that this diversity 'crash' is genuine (Figs 9-11), as is the resultant depauperate fauna throughout the earliest Cretaceous. The J/K event coincides with the replacement of non-neosauropods, basal macronarians and diplodocids [but see Upchurch \& Mannion (2009) regarding the fossil record of the latter clade] by other derived neosauropods (predominantly titanosauriforms). Although Raup \& Sepkoski (1986) included the J/K boundary as one of their eight major episodes of marine extinction in the last $250 \mathrm{Myr}$, most subsequent studies have regarded it as only a minor event (e.g. Hallam \& Wignall, 1997; Bambach, 2006; Arens \& West, 2008; but see Orcutt, Sahney \& Lloyd, 2007, and Benson et al., 2010, for recent dissenting views). As well as the demise of certain sauropod groups, stegosaur diversity was also greatly reduced at the J/K boundary (Bakker, 1978; Galton \& Upchurch, 2004b), although why the diversity of other dinosaur clades remained unaffected (Barrett et al., 2009; Butler et al., 2009a) is difficult to determine; it may relate to differences in the feeding strategies and/or preferred plant fodder of stegosaurs and certain sauropod groups relative to other ornithischian clades and sauropods with narrow tooth crowns that survived into the Cretaceous (see also discussions in Barrett \& Willis, 2001; Butler et al., 2009a).

Rarefaction and the WPDE show a small peak in diversity in the Aptian (125.0-112.0 Myr), whereas diversity in the UPDE remains the same as in the Barremian (Fig. 6). Both PDEs indicate a drop in the Albian (112.0-99.6 $\mathrm{Myr}$ ), whereas rarefied diversity in this stage cannot be distinguished from Early Cretaceous levels (Fig. 10). Residuals, on the other hand, suggest that both of these time periods are at least partly controlled by sampling biases (Fig. 9).

\section{(f) Late Cretaceous}

Diversity remains low during the Cenomanian-Santonian (99.6-83.5 Myr) in both the UPDE and WPDE (Fig. 6), whereas residuals indicate that much of this time interval is influenced by sampling biases (Fig. 9). Rarefaction does not enable differentiation of Cenomanian (99.6-93.5 Myr) or Santonian (85.8-83.5 Myr) diversity from that of the Albian or earliest Cretaceous levels, but Turonian-Coniacian (93.5-85.8 Myr) diversity is recovered as comparable with the Aptian (Fig. 10). A late Cenomanian marine extinction event has been noted by previous authors (Bambach, 2006; Arens \& West, 2008), but our data do not support a similar extinction for terrestrial taxa and Benson et al. (2010) have also cast doubt on the marine element of this extinction. Both PDEs show increases in sauropod diversity in the Campanian (83.5-70.6 Myr). The UPDE exhibits a drop in diversity from the late Campanian to the early Maastrichtian, whereas diversity remains constant in the WPDE. Each curve shows a decline in sauropod diversity in the late Maastrichtian before their demise at the K/P boundary (65.5 Myr; Fig. 6). Residuals indicate low diversity in the early Campanian and late Maastrichtian, with the time interval in-between (i.e. late Campanian-early Maastrichtian) affected to some degree by sampling biases (Fig. 9). Rarefaction shows diversity levels indistinguishable from the Aptian and there is no evidence for a decline in diversity across the Campanian-Maastrichtian (Fig. 10). The Maastrichtian drop in diversity observed in the PDEs (Fig. 6) may result from the Signor-Lipps effect (Signor \& Lipps, 1982; Lane et al., 2005; see also Barrett et al., 2009). Specifically, in the Maastrichtian (in the leadup to the $\mathrm{K} / \mathrm{P}$ mass extinction event), there is a high probability that a taxon will be unsampled. Lane et al. (2005) underlined the point that at extinction events many taxa become extinct simultaneously: this results in an increase in 'zombie' lineages and has the effect of making a sudden mass extinction appear prolonged (Signor \& Lipps, 1982). Lane et al. (2005) also highlighted (and demonstrated through computer simulation) that an increased proportion of these 'zombie' lineages belong to terminal taxa at a mass extinction, and it is these that the PDE cannot account for.

\section{(2) Does our choice of phylogeny make a difference?}

Although most of the phylogenies used in this study result in approximately similar diversity curves, there are a number of times where they differ. In some instances this merely reflects the inclusion of a greater number of taxa, but in several timeintervals these dissimilarities are a result of key differences within the competing phylogenies: these are discussed below.

The UPDE and YPDE curves match each other extremely closely throughout much of the time period under investigation (Table 2), although the YPDE tends to estimate a higher number of lineages throughout. This may partly reflect the greater number of taxa (32) incorporated into the Yates (2007) analysis compared to that of Upchurch et al. (2007) (26 taxa), but also the pectinate nature of the former phylogeny, which results in an increased number and duration of ghost lineages. Similarly, following an increase in the Hettangian (199.6-196.5 Myr), the UPDE curve remains relatively flat, while the YPDE continues to decline from the Norian (216.5-203.6 Myr) peak until a diversity increase in the Pliensbachian (189.6-183.0 Myr; Fig. 6). This difference in timing perhaps relates to the inclusion of different taxa, but probably more strongly reflects a lack of resolution among more derived taxa in the Yates (2007) tree.

The UPDE recovered an Aalenian (175.6-171.6 Myr) diversity peak, which is not found in the WPDE (Fig. 6). This peak is almost entirely caused by the inclusion of the Middle Jurassic Chinese taxon Bellusaurus (Dong, 1992; Zhao, 1993; Weishampel et al., 2004a; see discussion in Upchurch \& Barrett, 2005) in the former analysis. Upchurch et al. (2004) recovered it as a basal macronarian (see Fig. 1), representing a very derived position for a Middle Jurassic sauropod. This combination has the effect of extending all neosauropod (and some eusauropod) lineages back into the Aalenian (Upchurch \& Barrett, 2005). However, re-analysis of the Upchurch et al. (2004) data matrix has placed Bellusaurus outside of Neosauropoda (see Fig. 1; Wilson \& Upchurch, 2009), which would remove the difference between the two diversity curves. 
In most time bins the LPDE is significantly inflated, even compared to the TDE: this is unexpected given that the latter contains 76 more sauropodomorph taxa than the supertree (Figs 5, 6). The main departure occurs in the late Early Cretaceous: the LPDE shows a prominent diversity peak in the Valanginian-Barremian (140.2-125.0 Myr) not seen in the WPDE or UPDE, although minor peaks have been noted for this time period before (Hunt et al., 1994; Barrett \& Willis, 2001). Lloyd et al. (2008) suggested that this Valanginian peak may reflect the origination of Lithostrotia (see Fig. 1), although (aside from the 'Toba sauropod' discussed below) definite lithostrotian remains are yet to be recovered from earlier than the Barremian ('Titanosaurus valdensis' from the Isle of Wight, UK: Huene, 1929; Wilson \& Upchurch, 2003). Both the overall diversity inflation and the late Early Cretaceous peak in the LPDE are caused by the reconstruction of extensive and numerous ghost lineages, many of which are based on doubtful phylogenetic relationships in the supertree. For example, the inclusion of the Early Cretaceous 'Toba sauropod' (Tomida \& Tsumura, 2006) as a derived taxon (i.e. Lithostrotia) in the supertree, pulls nearly all titanosaur lineages back into the Hauterivian (136.4-130.0 Myr). However, this taxon is extremely fragmentary and has not been rigorously placed in a phylogeny. Furthermore, the preserved material shows no evidence to suggest referral to Lithostrotia, and it probably represents either a basal titanosaur (Tomida \& Tsumura, 2006) or titanosauriform (Wilson \& Upchurch, 2009). Other ghost lineages in the LPDE are produced by unusual groupings of taxa, e.g. the Nemegtosauridae being recovered as the sister taxon to Bellusaurus + traditional titanosaurs, which pulls some of these clades back into the Aalenian. The production of novel clades, not seen in any of the source trees, is one of the key problems in the construction of supertrees (Bininda-Emonds \& Bryant, 1998; Pisani \& Wilkinson, 2002; Pisani et al., 2002). The extensive ghost lineages suggest that the late Early Cretaceous diversity peak of the LPDE is probably a partial artefact of an inaccurate phylogeny (Wills, 2007). This is also supported by the lack of correlation in the Cretaceous between the LPDE and TDE, even when the latter is restricted to just those taxa present in the former. Additionally, the LPDE deviates noticeably from the overall non-avian dinosaur diversity curve of Lloyd et al. (2008), suggesting that the study of different taxonomic rankings of dinosaurs will better elucidate fluctuations in dinosaur diversity (see also Barrett et al., 2009).

The UPDE suggests a slight recovery in diversity by the Turonian (93.5-89.3 Myr) compared to the WPDE (Fig. 6); however, this 'recovery' results from the 'diplodocoid' nemegtosaurid ghost lineage extending from the Campanian (83.5-70.6 Myr) to the Oxfordian (161.2-155.7 Myr; Upchurch et al., 2004), whereas nemegtosaurids have now been convincingly allied with titanosaurs (see Fig. 1; Curry Rogers \& Forster, 2001; Curry Rogers, 2005; Wilson, 2005).

Although it appears that phylogenetic structure does make a difference when constructing diversity curves, the effect is relatively minor in most instances. However, the use of supertrees is much more problematic, and we recommend using supermatrices or bolting together compatible phylogenies (e.g. Upchurch et al., 2004, 2007) as more suitable alternatives.

\section{(3) Did sea level control sauropodomorph diversity?}

Previous authors (Haubold, 1990; Hunt et al., 1994; Barrett \& Willis, 2001; Upchurch \& Barrett, 2005) have commented on the correlation of a number of peaks and troughs in sauropodomorph diversity with fluctuations in sea level (see Section I). Of these, only the Kimmeridgian (155.7-150.8 Myr) seems to show a correspondence between high diversity and high sea level in the updated analyses (Fig. 11). This correlation suggests that sea level changes could be exerting a genuine biotic effect on diversity: high sea levels might have led to the isolation of terrestrial areas, resulting in allopatric speciation. The sea level regression in the late Maastrichtian (67.5-65.5 Myr) in the Haq et al. (1987) curve may coincide with a decline in diversity, although, as noted above, the different methods and proxies yield conflicting signals for this time period. Additionally, there is no decline evident at this time in the Miller et al. (2005) curve (Fig. 11), suggesting that this posited regression may be erroneous. If this drop in sea level is genuine though, then it might have enabled the biotic mixing of previously separate regions, leading to extinction (Bakker, 1977; Horner, 1983; Weishampel \& Horner, 1987; Upchurch \& Barrett, 2005). Although there is no apparent correspondence between peaks and troughs in the Early Cretaceous, statistical comparisons do suggest that sea level may be controlling genuine diversity fluctuations during this epoch.

Over most of sauropodomorph evolutionary history, fluctuations in 'corrected' diversity patterns no longer display convincing correlations with sea level. In particular, several time intervals represent periods of high diversity during low sea level (late Norian and Bathonian-Callovian), while other depauperate times coincide with high sea level (Oxfordian, Berriasian and Cenomanian-Santonian). These negative correlations may reflect the biotic effect of fluctuating sea levels, i.e. high sea levels can also result in the reduction of habitat size, leading to extinction (Dodson, 1990; Upchurch \& Barrett, 2005). However, abiotic factors may also play a role, i.e. high sea levels result in a diminished terrestrial record and low sea levels result in an improved record (Markwick, 1998). During the Jurassic and Early Cretaceous, however, the dominant effect of sea level on diversity appears to be biotic.

The late Turonian (91.4-89.3 Myr) and late Coniacian (87.55-85.8 Myr) represent the lowest sea levels for the Late Cretaceous in the Miller et al. (2005) sea-level curve (Fig. 11). Previous authors (Haubold, 1990; Hunt et al., 1994; Upchurch \& Barrett, 2005) have noted that this corresponds with a decline in sauropod diversity; however, 'corrected' diversity during this time interval is at least comparable to the Cenomanian (99.6-93.5 Myr) and Santonian (85.8-83.5 Myr) (both representing times of higher sea levels) (Figs 6, 9, 10). These authors (Haubold, 
1990; Hunt et al., 1994; Upchurch \& Barrett, 2005) also commented on the correlation between high sea levels and high sauropod diversity in the Campanian-Maastrichtian (83.5-65.5 Myr). This time interval does represent a period of higher sea level than most Late Cretaceous stages in the Miller et al. (2005) sea-level curve, which suggests there may still be some correlation. However, the comparably depauperate Cenomanian records considerably higher sea levels than the Campanian-Maastrichtian (Fig. 11), and there is still no statistical correlation between sea level and diversity for the Late Cretaceous when the Cenomanian is excluded. This overall lack of correlation in the Late Cretaceous supports recent work suggesting that titanosaurs (which constituted nearly all Late Cretaceous sauropods) showed a preference for inland terrestrial environments (Mannion, 2008; Mannion \& Upchurch, 2010a), and thus we might expect sea level to have a more limited or indirect effect on their diversity relative to non-titanosaurian sauropods living in many coastal habitats.

The lack of support for other previously reported correlations is possibly a consequence of changes in the geological timescale since that of Haq et al. (1987) (see Section II. 4). Finally, it should be noted that there is no correlation between the Late Cretaceous sea-level curves of Miller et al. (2005) and Haq et al. (1987) (see Table 4). This discrepancy suggests that future studies may produce different sea-level curves for the rest of the Mesozoic too, which could challenge some of the above conclusions.

\section{(4) Good rock record versus poor fossil dating}

An additional issue, which must at least partly have an impact on our diversity curves, relates to problems with the dating of many fossil-bearing localities (see also Section II. $2 d$ ). Several stages with good rock records (e.g. the Oxfordian; Upchurch \& Barrett, 2005; Mannion \& Upchurch, 2010b) have low observed and 'corrected' diversity, suggesting that these are genuinely depauperate time periods. However, it is possible that the inferred diversity of at least some of these time intervals has been adversely affected by uncertainties in rock dating. For example, as noted above (and in previous studies), sauropod diversity is extremely low in the Oxfordian (161.2-155.7 Myr), yet it is possible that many Late Jurassic outcrops dated as Kimmeridgian-Tithonian (155.7-145.5 Myr) actually also include Oxfordian sediments. The Late Jurassic Morrison Formation of North America provides a suitable case study: this formation has produced 11 of the 175 genera included in this study and is generally considered Kimmeridgian-Tithonian in age (see reviews in Kowallis et al., 1998; Weishampel et al., 2004b). However, a recent study using Uranium/Lead (U/Pb) Sensitive high-resolution ion microprobe (SHRIMP) analyses of eight individual zircon crystals collected from the upper third of the formation (exposed at Ninemile Hill, near Medicine Bow, southeastern Wyoming) yielded a date of 156.3 +/- 2 Myr, which indicates that at least some of the Morrison Formation is probably Oxfordian (Trujillo, Chamberlain \& Strickland, 2006). Earlier studies have also hinted at the possibility of an
Oxfordian age for the lower parts of the formation (Imlay, 1980; Kowallis et al., 1998; Litwin, Turner \& Peterson, 1998; Schudack, Turner \& Peterson, 1998). There may be similar problems in Late Jurassic outcrops in other countries (e.g. China and Europe), as well as other time periods (e.g. the Early Cretaceous of North America, as well as the Cretaceous of China and South America). This is an effect that cannot be accounted for by the current analyses and raises issues regarding the accuracy of some of the reconstructed diversity patterns. While this is an important issue that should be considered in all future analyses of palaeodiversity, we suspect that uncertainties in the stratigraphic ages of fossiliferous rocks produce relatively fine-grained errors and are unlikely to obscure major evolutionary and extinction events (at least when sample sizes are large).

\section{(5) Methodological choices}

\section{(a) Different approaches to correcting diversity}

The three methods utilised here for 'correcting' diversity (PDE, residuals and rarefaction) all capture different aspects of sampling biases and thus each has its benefits. Phylogeny may be detached from sampling in the strictest sense, but its inference of ghost lineages fills gaps in our sampling of the fossil record and is particularly useful for elucidating diversity in time periods with a poor rock record. Residuals allow us to 'remove' sampling biases from observed diversity, enabling us to investigate how diversity might appear given an unbiased record, while problems pertaining to varying sample size can be resolved through rarefaction. Each method also has its problems (see Section II) but use of all three techniques allows us to benefit from each of their strengths and enables recognition of diversity peaks and troughs common to all.

In the case of rarefaction, we believe that the 'alloccurrences' analysis is a more meaningful way of implementing rarefaction than the 'genus-only' analysis in that it includes material that must represent an additional taxon, even if this cannot be diagnosed; thus it attempts to capture 'cryptic' diversity.

\section{(b) Time-slicing}

Although previous studies have described and compared individual peaks and troughs in diversity and sampling proxies (e.g. Upchurch \& Barrett, 2005; Barrett et al., 2009; Butler et al., 2009c), statistical comparisons have usually been restricted to the full time interval under investigation (e.g. the Late Triassic-Late Cretaceous in the case of Barrett et al., 2009) (see Benson et al., 2010, for an exception). It is possible that such a comparison will produce nonsignificant results because the particular sampling bias does not affect diversity throughout the full time period under investigation. However, if this bias exerted an influence for just the Cretaceous, for example, then any signal might be obscured by the remaining time interval. This problem can be ameliorated by time-slicing the statistical correlations, as has been implemented in the current study (see also Benson et al., 
2010; Mannion \& Upchurch, 2010a). There are a number of examples where a full Mesozoic comparison has resulted in no relationship, while consideration of a smaller time bin has demonstrated a strong correlation (e.g. TDE versus DBFs for the Cretaceous: Table 3). This approach could have implications for recent studies (e.g. Marx, 2009), which have reported no statistical correlation between diversity and sampling biases.

\section{GONGLUSIONS}

(1) Through comparison of a number of different sampling proxies and use of several methods, there are certain time periods for which sauropodomorph diversity seems to reflect genuine biological effects rather than the vagaries of the fossil record. Peaks are consistently recovered for the Pliensbachian-Toarcian, Bathonian-Callovian and Kimmeridgian-Tithonian, suggesting that these represent time intervals of genuinely high sauropodomorph diversity, as also indicated by previous authors (e.g. Hunt et al., 1994; Barrett \& Willis, 2001; Upchurch \& Barrett, 2005; Barrett et al., 2009). The Oxfordian is repeatedly shown to represent a depauperate fauna, despite an apparently good rock record at this time, which is consistent with the study of Upchurch \& Barrett (2005), although issues remain regarding the poor dating of some fossil-bearing localities. Similarly, the $\mathrm{J} / \mathrm{K}$ boundary appears to represent a real crash in sauropod diversity, supporting the findings of previous authors (e.g. Hunt et al., 1994; Upchurch \& Barrett, 2005; Barrett et al., 2009), and may be related to environmental shifts that adversely affected the food plants utilised by broad-crowned sauropods and stegosaurs. The observed diversity of the remaining portions of the Late Triassic-Jurassic seem to be largely controlled by sampling biases (Upchurch \& Barrett, 2005), although the Norian may at least represent a small peak in diversity.

(2) The Cretaceous record is more difficult to interpret as many of the sampling biases suggest contrasting fluctuations in diversity. The Berriasian-Barremian does appear to be an interval of genuinely low diversity. However, increased 'gappiness', at least in the very earliest part of the Early Cretaceous (i.e. the Berriasian), may be a result of a lack of preservation of the environments typically inhabited by sauropods, rather than true fluctuations in diversity. Nevertheless, this cannot account for the remainder of the earliest Cretaceous, indicating that this represented a depauperate time interval. This contrasts with previous studies that have proposed a diversity peak in the Valanginian-Barremian (Hunt et al., 1994; Barrett \& Willis, 2001; Lloyd et al., 2008). The Aptian-Albian may represent a genuine peak in diversity; however, at least some of this appears to be influenced by sampling biases (Upchurch \& Barrett, 2005), suggesting it may only be a small peak. Diversity in the Cenomanian-Santonian is difficult to elucidate, with rarefaction suggesting moderately high diversity whereas residuals indicate relatively low diversity. However, this time period has been overlooked in comparison to many other Mesozoic intervals, with few diagnostic remains known until relatively recently (Mannion \& Upchurch, 2010b), and poor exposures in many parts of the world (i.e. Europe and North America); thus, it is possible that this portion of the early Late Cretaceous terrestrial record remains undersampled.

(3) The PDE shows an incremental increase in diversity from the early Campanian to the late Campanian. This is followed by a slight decline in the early Maastrichtian, before diversity plummets in the late Maastrichtian. However, this drop in the PDE is likely to be a result of the Signor-Lipps effect. Residuals, on the other hand, suggest low diversity in the early Campanian, but then produce contradictory signals for the late Campanian-early Maastrichtian. Rarefaction does not recover higher diversity levels than the rest of the mid-Late Cretaceous and finds no evidence for a Campanian-Maastrichtian decline. It seems likely that at least some of these latest Cretaceous diversity levels are the product of sampling biases (Upchurch \& Barrett, 2005).

(4) Although the western European rock record is not a useful proxy for global sauropodomorph diversity, it is closely correlated with the diversity of taxa from this region. This suggests that a global compilation of rock outcrop area may provide a strong correlation with global diversity (Haubold, 1990; Wall et al., 2009); however, testing of this hypothesis is not possible at the moment because stage-level global rock outcrop metrics are currently unavailable. It would be useful for future studies to consider similar comparisons for other regions (McGowan \& Smith, 2008; Mannion, 2009b), given that no single region may provide a sufficiently accurate proxy for global diversity (see also Jackson \& Johnson, 2001; Vermeij \& Leighton, 2003).

(5) There is evidence to suggest that sea level affects sauropodomorph diversity biotically. A Kimmeridgian diversity peak and (putative) late Maastrichtian decline correspond to a rise and fall of sea level, respectively. Terrestrial regions may have become isolated in the Kimmeridgian as a consequence of high sea level, resulting in allopatric speciation, while a late Maastrichtian regression may have led to extinction events as a consequence of the mixing of biotas from previously isolated areas (Bakker, 1977; Horner, 1983; Weishampel \& Horner, 1987; Upchurch \& Barrett, 2005). Several time intervals represent negative correlations between diversity and sea level: these may also reflect biotic events, in that marine transgressions decrease habitat size and can lead to extinction 
(Dodson, 1990; Upchurch \& Barrett, 2005), and it seems that sea level affected diversity biotically during the Jurassic-Early Cretaceous.

(6) Most previous analyses have used only one technique for correcting diversity: this study illustrates that comparison and use of multiple proxies and methods is imperative in any attempt to discriminate genuine diversity from the biases of our uneven sampling of the rock record. Furthermore, these analyses highlight the importance of looking at particular taxonomic groups (i.e. sauropodomorphs) in conjunction with more inclusive clades (i.e. dinosaurs). Although analysing a single group of animals in isolation may have limitations in terms of elucidating general macroevolutionary patterns (i.e. the results may only show what that particular group is doing), at a broader scale fluctuations in one group can be obscured by signals in others. For sauropodomorphs, this seems to be particularly problematic, as previous studies have noted that their diversity does not correlate strongly with that of ornithischians and theropods (Weishampel \& Jianu, 2000; Upchurch \& Barrett, 2005; Barrett et al., 2009). However, more rigorous testing of the effects of sampling for these two groups is also required.

\section{ACKNOWLEDGEMENTS}

We would like to express particular thanks to all those who allowed the study of dinosaur material in their care. Advice on statistical tests by Alistair J. McGowan is very much appreciated and reviews by David E. Fastovsky and Andrew B. Smith greatly improved this work. Jerald D. Harris is also thanked for assistance with references. P.D.M. is supported by a University College London NERC studentship (NER/S/A/2006/14347). P.U. wishes to thank The Palaeontological Association, The Abbey International Collaborative Grant scheme and The Royal Society for funds that have enabled travel to examine sauropodomorph specimens.

\section{REFERENGES}

Adrain, J. M. \& Westrop, S. R. (2000). An empirical assessment of taxic paleobiology. Science 289, 110-112.

Adrain, J. M., Westrop, S. R., Chatterton, B. D. E. \& RAMSKÖLD, L. (2000). Silurian trilobite alpha diversity and the end-Ordovician mass extinction. Paleobiology 26, 625-646.

Alroy, J., Aberhan, M., Bottjer, D. J., Foote, M., Fürsich, F. T., Harries, P.J., Hendy, A.J. W., Holland, S. M., Ivany, L. C., Kiessling, W., Kosnik, M. A., Marshall, C. R., Mggowan, A.J., Miller, A. I., Olszewski, T. D., Patzkowsky, M. E., Peters, S. E., Villier, L., Wagner, P. J., Bonuso, N., Borkow, P. S., Brenneis, B., Clapham, M. E., Fall, L. M., Ferguson, C. A., Hanson, V. L., Krug, A. Z., Layou, K. M., Leckey, E. H., Nürnberg, S., Powers,
C. M., Sessa, J. A., Simpson, C., Tomašových, A. \& Visaggi, C. C. (2008). Phanerozoic trends in the global diversity of marine invertebrates. Science 321, 97-100.

Alroy, J., Marshall, C. R., Bambach, R. K., Bezusko, K., Foote, M., Fürsich, F. T., Hansen, T. A., Holland, S. M., Ivany, L. C., Jablonski, D., Jacobs，D. K., Jones，D. C., Kosnik, M. A., Lidgard, S., Low, S. A., Miller, I., NovackGottshall, P. M., Olszewski, T. D., Patzkowsky, M. E., Raup, D. M., Roy, K., Sepkoski, JR., J.J., Sommers, M. G., Wagner, P.J. \& Webber, A. (2001). Effects of sampling standardization on estimates of Phanerozoic marine diversification. Proceedings of the National Academy of Sciences, USA 98, 6261-6266.

Archibald, J. D. (2005). Shape of Mesozoic dinosaur richness: Comment and reply. Geology 32, 74-75.

Arens, N. G. \& West, I. D. (2008). Press-pulse: a general theory of mass extinction? Paleobiology 34, 456-471.

BAKker, R. T. (1977). Tetrapod mass extinctions-Model of the regulation of speciation rate and immigration by cycles of topographic diversity. In Patterns of Evolution (Hallam, A., eds.), pp. 439-468. Elsevier, Amsterdam.

BAKkeR, R. T. (1978). Dinosaur feeding behaviour and the origin of flowering plants. Nature 274, 661-663.

BAмвACH, R. K. (2006). Phanerozoic biodiversity: mass extinctions. Annual Review of Earth and Planetary Science 34, 127-155.

Barrett, P. M., McGowan, A. J. \& Page, V. (2009). Dinosaur diversity and the rock record. Proceedings of the Royal Society of London, Series B 276, 2667-2674.

Barrett, P. M. \& Upchurch, P. (2005). Sauropod diversity through time: possible macroevolutionary and palaeoecological implications. In The Sauropods: evolution and paleobiology (CURRYRogers, K. A. \& Wilson, J. A., eds.), pp. 125-156. University of California Press, Berkeley.

Barrett, P. M. \& Willis, K. J. (2001). Did dinosaurs invent flowers? Dinosaur-angiosperm coevolution revisited. Biological Reviewes 76, 411-447.

Behrensmeyer, A. K., Kidwell, S. M. \& Gastaldo, R. A. (2000). Taphonomy and paleobiology. Paleobiology 26 (Deep Time: Paleobiology's Perspective, supplement to no. 4), 101-147.

Benson, R. J. B., Butler, R. J., Lindgren, J. \& Smith, A. S. (2010). Mesozoic marine tetrapod diversity: mass extinctions and temporal heterogeneity in geological megabiases affecting vertebrates. Proceedings of the Royal Society of London, Series B 277, 829-834.

Benton, M. J. (1994). Late Triassic to Middle Jurassic extinctions among continental tetrapods: testing the pattern. In In the Shadow of Dinosaurs (Fraser, N. C. \& Sues, H.-D., eds.), pp. 366-397. Cambridge University Press, Cambridge.

Benton, M.J. (1996). On the nonprevalence of competitive replacement in the evolution of tetrapods. In Evolutionary Paleobiology (Jablonski, D., Erwin, D. H. \& Lipps, J. H., eds.), pp. 185-210. University of Chicago Press, Chicago.

Benton, M.J. (1998). The quality of the fossil record of vertebrates. In The adequacy of the fossil record (Donovan, S. K. \& Paul, G. R. C., eds.), pp. 269-303. Wiley, New York.

Benton, M.J. (2001). Finding the tree of life: matching phylogenetic trees to the fossil record through the $20^{\text {th }}$ century. Proceedings of the Royal Society of London, Series B 268, 2123-2130.

Benton, M. J. (2008). Fossil quality and naming dinosaurs. Biology Letters 4, 729-732.

Benton, M. J., Juul, L., Storrs, G. W. \& Galton, P. M. (2000). Anatomy and systematics of the prosauropod dinosaur 
Thecodontosaurus antiquus from the Upper Triassic of southwest England. Fournal of Vertebrate Paleontology 20, 77-108.

Benton, M. J. \& Storrs, G. W. (1994). Testing the quality of the fossil record-paleontological knowledge is improving. Geology 22, $111-114$.

Bininda-Emonds, O. R. \& Bryant, D. (1998). Properties of matrix representation with parsimony analyses. Systematic Biology 47, 497-508.

Brochu, G. A. \& Norell, M. A. (2000). Temporal congruence and the origin of birds. Fournal of Vertebrate Paleontology 20, 197-200.

Butler, R. J., Barrett, P. M., Kenrick, P. \& Penn, M. G. (2009a). Diversity patterns amongst dinosaurs and plants during the Cretaceous: implications for hypotheses of dinosaur/angiosperm co-evolution. Fournal of Evolutionary Biology 22, 446-459.

Butler, R. J., Barrett, P. M., Kenrick, P. \& Penn, M. G. (2009b). Testing co-evolutionary hypotheses over geological timescales: interactions between Mesozoic non-avian dinosaurs and cycads. Biological Reviewes 84, 73-89.

Butler, R. J., Barrett, P. M., Nowbath, S. \& Upchurch, P. (2009c). Estimating the effects of the rock record on pterosaur diversity patterns: implications for hypotheses of bird/pterosaur competitive replacement. Paleobiology 35, 432-446.

Carrano, M. T. (2008a). Patterns of diversity among latest Cretaceous dinosaurs in North America. Fournal of Vertebrate Paleontology 28 (supplement to no. 3), 61A.

Carrano, M. T. (2008b). Taxonomy and classification of nonavian Dinosauria. Paleobiology Database Online Systematics Archive 4 (www.paleodb.org).

Collinson, M. E. \& Hooker, J.J. (1991). Fossil evidence of interactions between plants and plant-eating mammals. Philosophical Transactions of the Royal Society of London, Series B 333, 197-208.

Colwell, R. K. \& Coddington, J. A. (1994). Estimating terrestrial biodiversity through extrapolation. Philosophical Transactions of the Royal Society of London, Series B 345, 101-118.

Crampton, J. S., Beu, A. G., Cooper, R. A., Jones, C. M., Marchall, B. \& Maxwell, D. P. A. (2003). Estimating the rock volume bias in paleobiodiversity studies. Science 301, $358-360$.

Curry Rogers, K. A. (2005). Titanosauria: a phylogenetic overview. In The Sauropods: evolution and paleobiology (CURRYRogers, K. A. \& Wilson, J. A., eds.), pp. 50-103. University of California Press, Berkeley.

Curry Rogers, K. A. \& Forster, C. (2001). The last of the dinosaur titans: a new sauropod from Madagascar. Nature 412, 530-534.

Davis, E. B. \& Pyenson, N. D. (2007). Diversity biases in terrestrial mammalian assemblages and quantifying the differences between museum collections and published accounts: A case study from the Miocene of Nevada. Palaeogeography, Palaeoclimatology, Palaeoecology 250, 139-149.

Dodson, P. (1990). Counting dinosaurs: how many kinds were there? Proceedings of the National Academy of Sciences, USA 87, $7608-12$

Dodson, P. \& Dawson, S. D. (1991). Making the fossil record of dinosaurs. Modern Geology 16, 3-15.

Dong, Z.-M. (1992). Dinosaurian Faunas of China. China Ocean Press, Beijing.

Fastovsky, D. E., Huang, Y., Hsu, J., Martin-Mcnaughton, J., Sheehan, P. M. \& Weishampel, D. B. (2004). Shape of Mesozoic dinosaur richness. Geology 32, 877-880.
Flynn, J. J., Nesbitt, S., Parrish, J. M., Ranivoharimanana, L. \& Wyss, A. R. (2008). A new species of basal archosauromorph from the Late Triassic of Madagascar. Fournal of Vertebrate Paleontology 28 (Supplement to no. 3), 78A.

Flynn, J. J., Parrish, J. M., Rakotosamimanana, B., Simpson, W. F., Whatley, R. L. \& Wyss, A. R. (1999). A Triassic fauna from Madagascar, including early dinosaurs. Science $\mathbf{2 8 6}$, $763-765$.

Foote, M. (1992). Rarefaction analysis of morphological and taxonomic diversity. Paleobiology 18, 1-16.

Foote, M. (1996). Perspective: evolutionary patterns in the fossil record. Evolution 50, 1-11.

Forey, P. L., Fortey, R. A., Kenrick, P. \& Smith, A. B. (2004). Taxonomy and fossils: a critical appraisal. Philosophical Transactions of the Royal Society of London, Series B 359, 639-653.

Fountaine, T. M. R., Benton, M.J., Dyke, G.J. \& Nudds, R. L. (2005). The quality of the fossil record of Mesozoic birds. Proceedings of the Royal Society of London, Series B 272, 289-294.

Fröbisch, J. (2008). Global taxonomic diversity of anomodonts (Tetrapoda, Therapsida) and the terrestrial rock record across the Permian-Triassic boundary. PloS ONE 3, e3733. doi:10.1371/journal.pone.0003733.

Galton, P. M. \& Upchurch, P. (2004a). Prosauropoda. In The Dinosauria, $1^{\text {st }}$ Edition (Weishampel, D. B., Dodson, P., \& Osmólska, H., eds.), pp. 232-258. University of California Press, Berkeley.

Galton, P. M. \& Upchurch, P. (2004b). Stegosauria. In The Dinosauria, $1^{\text {st }}$ Edition (Weishampel, D. B., Dodson, P., \& Osmólska, H., eds.), pp. 343-362. University of California Press, Berkeley.

Gauthier, J. (1986). Saurischian monophyly and the origin of birds. Memoirs of the California Academy of Sciences 8, 1-55.

Gotelli, N. \& Colwell, R. K. (2001). Quantifying biodiversity: procedures and pitfalls in the measurement and comparison of species richness. Ecology Letters 4, 379-391.

Gradstein, F. M., OGg, J. G. \& Smith, A. G. (2005). A geological timescale 2004. Cambridge University Press.

Hallam, A. (1989). The case for sea level change as a dominant causal factor in mass extinction of marine invertebrates. Philosophical Transactions of the Royal Society of London Series B 325, $437-455$.

Hallam, A. \& Wignall, P. B. (1997). Mass extinctions and their aftermath. Oxford University Press.

Hammer, Ø. \& Harper, D. A. T. (2006). Paleontological Data Analysis. Blackwell Publishing, Oxford.

Hammer, Ø., Harper, D. A. T. \& Ryan, P. D. (2001). PAST: Paleontological Statistics Software Package for Education and Data Analysis. Palaeontologia Electronica 4, 9.

HaQ, B. U., Hardenbol, J. \& Vail, P. R. (1987). Chronology of fluctuating sea levels from the Triassic. Science 235, 1156-1167.

Harries, P.J. \& Little, G. T. S. (1999). The early Toarcian (Early Jurassic) and the Cenomanian-Turonian (Late Cretaceous) mass extinctions: similarities and contrasts. Palaeogeography, Palaeoclimatology, Palaeoecology 154, 39-66.

Haubold, H. (1990). Dinosaurs and fluctuating sea levels during the Mesozoic. Historical Biology 4, 75-106.

Heck, K. L. J., Van Belle, G. \& Simberloff, D. (1975). Explicit calculation of rarefaction diversity measurement and the determination of sufficient sample size. Ecology 56, 1459-1461.

Hennig, W. (1965). Phylogenetic systematics. University of Illinois Press, Urbana.

Horner, J. R. (1983). Cranial osteology and morphology of the type specimen of Maiasaura peeblesorum (Ornithischia: 
Hadrosauridae), with discussion of its phylogenetic position. Fournal of Vertebrate Paleontology 3, 29-38.

Huene, F. v. (1929). Los saurisquios y ornitisquios del Cretáceo Argentino. Anales del Museo de La Plata (Series 3) 3, 1-196.

Hunt, A. P., Lockley, M. G., Lucas, S. G. \& Meyer, G. A. (1994). The global sauropod fossil record. GAIA 10, 261-279.

Hurlbert, S. H. (1971). The nonconcept of species diversity: a critique and alternative parameters. Ecology 52, 577-586.

ImLAY, R. W. (1980). Jurassic paleobiogeography of the conterminous United States in its continental setting. U.S. Geological Survey Professional Paper 1062, 1-134.

Jablonski, D. (2005). Mass extinctions and macroevolution. Paleobiology 31, 92-210.

Jablonski, D., Erwin, D. H. \& Lipps, J. H. (1996). Evolutionary paleobiology. University of Chicago Press, Chicago.

Jackson, J. B. C. \& Johnson, K. G. (2001). Measuring past biodiversity. Science 293, 2401-2404.

Johnson, J. G. (1974). Extinction of perched faunas. Geology 2, $479-482$.

Kalmar, A. \& Currie, D.J. (2010). The completeness of the continental fossil record and its impact on patterns of diversification. Paleobiology 36, 51-60.

Kowallis, B., Christiansen, E. H., Deino, A. L., Peterson, F., Turner, C. E., Kunk, M.J. \& Obradovich, J. D. (1998). The age of the Morrison Formation. Modern Geology 22, 235-260.

Krebs, C. J. (1999). Ecological methodology ( $2{ }^{\text {nd }}$ Edition). Addison Wesley Longman, California.

Lane, A., Janis, C. M. \& Sepkoski, JR. J. J. (2005). Estimating paleodiversities: a test of the taxic and phylogenetic methods. Paleobiology 31, 21-34.

Langer, M. A., Abdala, F., Richter, M. \& Benton, M. J. (1999). A sauropodomorph dinosaur from the Upper Triassic (Carnian) of southern Brazil. Comptes rendus de l'Academie des Sciences, Paris, Sciences de la Terre et des Planètes 329, 511-517.

Levinton, J. (1988). Genetics, paleontology, and macroevolution. Cambridge University Press, Cambridge.

Litwin, R., Turner, C. E. \& Peterson, F. (1998). Palynological evidence on the age of the Morrison Formation. Modern Geology 22, 297-320.

Lloyd, G. T., Davis, K. E., Pisani, D., Tarver, J. E., Ruta, M., Sakamoto, M., Hone, D. W. E., Jennings, R. \& Benton, M. J. (2008). Dinosaurs and the Cretaceous Terrestrial Revolution. Proceedings of the Royal Society of London, Series B 275, 2483-2490.

Lockley, M. G., Meyer, C. A., Hunt, A. P. \& Lucas, S. (1994). The distribution of sauropod tracks and trackmakers. GAIA 10, 233-248.

Macleod, N. \& Archibald, J. D. (2005). The decline and fall of the non-avian dinosaurs. Fournal of Vertebrate Paleontology 25 (Supplement to no. 3), 87A.

Mannion, P. D. (2008). Environmental associations of sauropod dinosaurs and their bearing on the early Late Cretaceous "sauropod hiatus". Fournal of Vertebrate Paleontology 28 (Supplement to no. 3), 111A.

Mannion, P. D. (2009a). A rebbachisaurid sauropod from the Lower Cretaceous of the Isle of Wight, England. Cretaceous Research 30, 521-526.

Mannion, P. D. (2009b). Review and analysis of African sauropodomorph dinosaur diversity. Palaeontologia Africana 44, $108-111$.
Mannion, P. D. \& Upchurch, P. (2010a). A quantitative analysis of environmental associations in sauropod dinosaurs. Paleobiology $36,253-282$.

Mannion, P. D. \& Upchurch, P. (2010b). Completeness metrics and the quality of the sauropodomorph fossil record through geological and historical time. Paleobiology 36, 283-302.

Markwick, P.J. (1998). Fossil crocodilians as indicators of Late Cretaceous and Cenozoic climates: implications for using palaeontological data in reconstructing palaeoclimate. Palaeogeography, Palaeoclimatology, Palaeoecology 137, 205-271.

Martinez, R. N. \& Alcober, O. A. (2009). A basal sauropodomorph (Dinosauria: Saurischia) from the Ischigualasto Formation (Triassic, Carnian) and the early evolution of Sauropodomorpha. PloS ONE 4, e4397. doi:10.1371/journal. pone.0004397.

Marx, F. G. (2009). Marine mammals through time: when less is more in studying palaeodiversity. Proceedings of the Royal Society of London, Series B 276, 887-892.

Mazzetta, G. V., Christiansen, P. \& Fariña, R. A. (2004). Giants and bizarres: Body size of some southern South American Cretaceous dinosaurs. Historical Biology 16, 71-83.

Mcgowan, A. J. \& Smith, A. B. (2008). Are global Phanerozoic marine diversity curves truly global? A study of the relationship between regional rock records and global Phanerozoic marine diversity. Paleobiology 34, 80-103.

Mcintosh, J. S. (1990). Sauropoda. In The Dinosauria, $1^{\text {st }}$ Edition (Weishampel, D. B., Dodson, P., \& Osmólska, H., eds.), pp. 345-401. Berkeley, University of California Press.

Miller, A. I. (2000). Conversations about Phanerozoic global diversity. Paleobiology 26 (Deep Time: Paleobiology's Perspective, supplement to no. 4), 53-73.

Miller, A. I. \& Foote, M. (1996). Calibrating the Ordovician radiation of marine life: implications for Phanerozoic diversity trends. Paleobiology 22, 304-309.

Miller, K. G., Kominz, M. A., Browning, J. V., Wright, J. D., Mountain, G. S., Katz, M. E., Sugarman, P.J., Cramer, B. S., Christieblick, N. \& Pekar, S. F. (2005). The Phanerozoic record of global sea level change. Science 310, 1293-1297.

Newell, N. D. (1952). Periodicity in invertebrate evolution. Fournal of Paleontology 26, 371-385.

Nopcsa, F. (1915). Die Dinosaurier der Siebenbürgischen Landesteile Ungarns. Mitteilungen aus den Fahrbuch der Königlich Ungarnischen Geologischen Reichsanstalt 23, 1-26.

Norell, M. A. (1992). Taxic origin and temporal diversity: the effect of phylogeny. In Extinction and phylogeny (Novacek, M.J. \& Wheeler, Q. D., eds.), pp. 89-118. Columbia University Press, New York.

Norell, M. A. (1993). Tree-based approaches to understanding history: comments on ranks, rules, and the quality of the fossil record. American Fournal of Science 293, 407-417.

Norell, M. A. (1996). Ghost taxa, ancestors, and assumptions: a comment on Wagner. Paleobiology 22, 453-455.

Norell, M. A. \& Novacek, M. J. (1992a). Congruence between superpositional and phylogenetic patterns: comparing cladistic patterns with fossil evidence. Cladistics 8, 319-337.

Norell, M. A. \& Novacek, M. J. (1992b). The fossil record and evolution: comparing cladistic and paleontologic evidence for vertebrate history. Science 255, 1690-1693.

NovaceK, M. J. \& Norell, M. A. (1982). Fossils, phylogeny, and taxonomic rates of evolution. Systematic Zoology 31, 266-275. 
Orcutt, J., SAhney, S. \& Lloyd, G. T. (2007). Tetrapod extinction across the Jurassic-Cretaceous boundary. Fournal of Vertebrate Paleontology 27 (Supplement to no. 3), 126A.

Pearson, D. A., Schaefer, T., Johnson, K. R., Nichols, D. J. \& Hunter, J. P. (2002). Vertebrate biostratigraphy of the Hell Creek Formation in southwestern North Dakota and northwestern South Dakota. In The Hell Creek Formation and the Cretaceous-Tertiary boundary in the Northern Great Plains: an integrated continental record of the end of the Cretaceous (Hartman, J. H., Johnson K. R. \& Nichols, D. J., eds.), pp. 145-167. Geological Society of America Special Paper 361.

Peters, S. E. (2005). Geological constraints on the macroevolutionary history of marine animals. Proceedings of the National Academy of Sciences, USA 102, 12326-12331.

Peters, S. E. (2008). Environmental determinants of extinction selectivity in the fossil record. Nature 454, 626-629.

Peters, S. E. \& Foote, M. (2001). Biodiversity in the Phanerozoic: a reinterpretation. Paleobiology 27, 583-601.

Peters, S. E. \& Foote, M. (2002). Determinants of extinction in the fossil record. Nature 416, 420-424.

Pisani, D. \& Wilkinson, M. S. (2002). Matrix representation with parsimony, taxonomic congruence, and total evidence. Systematic Biology 51, 151-155.

Pisani, D., Yates, A. M., Langer, M. \& Benton, M. J. (2002). A genus-level supertree of the Dinosauria. Proceedings of the Royal Society of London, Series B 269, 915-921.

Pol, D. \& Norell, M. A. (2006). Uncertainty in the age of fossils and the stratigraphic fit to phylogenies. Systematic Biology 55, 512-521.

Rauhut, O. W. (2003). The interrelationships and evolution of basal theropod dinosaurs. Special Papers in Palaeontology 69, 1-213.

Raup, D. M. (1972). Taxonomic diversity during the Phanerozoic. Science 177, 1065-1071.

Raup, D. M. (1975). Taxonomic diversity estimation using rarefaction. Paleobiology 1, 333-342.

Raup, D. M. (1976). Species diversity in the Phanerozoic; an interpretation. Paleobiology 2, 289-297.

Raup, D. M. (1991). The future of analytical paleobiology. In Analytical paleobiology (Gilinsky, N. L. \& Signor, P. W., eds.), pp. 207-216. Paleontological Society Short Courses in Paleontology 4.

Raup, D. M. \& Sepkoski, JR. J. J. (1986). Periodic extinction of families and genera. Science 231, 833-836.

Rhodes, M. C. \& Thayer, C. W. (1991). Mass extinctions: ecological selectivity and primary production. Geology 19, 877-880.

Riley, H. \& Stutchbury, S. (1836). A description of various fossil remains of three distinct saurian animals discovered in the autumn of 1834, in the Magnesian Conglomerate on Durdham Down, near Bristol. Proceedings of the Geological Society of London 2, 397-399.

Robeck, H. E., Maley, C. C. \& Donoghue, M.J. (2000). Taxonomy and temporal diversity patterns. Paleobiology 26, $171-187$.

Ronov, A. B., Khain, V. E., Balukhovsky, A. N. \& SeslavinSkY, K. B. (1980). Quantitative analysis of Phanerozoic sedimentation. Sedimentary Geology 25, 31 1-325.

SAdLer, P. M. (1981). Sediment accumulation rates and the completeness of stratigraphic sections. Fournal of Geology 89, $569-584$.

Salgado, L., Coria, R. A. \& Calvo, J. O. (1997). Evolution of titanosaurid sauropods. I: phylogenetic analysis based on the postcranial evidence. Ameghiniana 34, 3-32.
SAnders, H. L. (1968). Marine benthic diversity: A comparative study. Biometrics 25, 517-535.

Schindel, D. E. (1980). Microstratigraphic sampling and the limits of paleontological resolution. Paleobiology 6, 408-426.

Schudack, M., Turner, C. E. \& Peterson, F. (1998). Biostratigraphy, paleoecology, and biogeography of charophytes and ostracodes from the Upper Jurassic Morrison Formation, Western Interior, USA. Modern Geology 22, 379-414.

Sepkoski, JR. J.J. (1993). Ten years in the library: new data confirm paleontological patterns. Paleobiology 19, 43-51.

Sereno, P. C. (1997). The origin and evolution of dinosaurs. Annual Review of Earth and Planetary Sciences 25, 435-489.

Sereno, P. C. (1999). The evolution of dinosaurs. Science 284, 2137-2147.

Sereno, P. G., Wilson, J. A., Witmer, L. M., Whitlock, J. A., Maga, A., Ide, O. \& Rowe, T. A. (2007). Structural extremes in a Cretaceous dinosaur. PloS ONE 2, e1230, doi:10.1371/journal.pone.0001230.

Sheehan, P. M., Fastovsky, P. M., Hoffmann, R. G., Berghaus, C. B. \& Gabriel, D. L. (1991). Sudden extinction of the dinosaurs: Latest Cretaceous, Upper Great Plains, U.S.A. Science 254, 835-839.

Signor III, P. W. \& Lipps, J. H. (1982). Sampling bias, gradual extinction patterns, and catastrophes in the fossil record. In Geological implications of impacts of large asteroids and comets on the Earth (Silver, L. T. \& Schultz, P. H., eds.), pp. 291-296. Geological Society of America Special Publication 190.

Simberloff, D. S. (1972). Properties of the rarefaction diversity measurement. American Naturalist 106, 414-418.

Smith, A. B. (1994). Systematics and the Fossil Record-Documenting Evolutionary Patterns. Blackwell Scientific Publications, Oxford.

Smith, A. B. (2001). Large-scale heterogeneity of the fossil record: implications for Phanerozoic diversity studies. Philosophical Transactions of the Royal Society of London, Series B 356, 351-367.

Smith, A. B. (2007). Marine diversity through the Phanerozoic: problems and perspectives. Fournal of the Geological Society, London 164, 731-745.

Smith, A. B., Gale, A. S. \& Monks, N. E. A. (2001). Sea level change and rock record bias in the Cretaceous: a problem for extinction and biodiversity studies. Paleobiology 27, 241-253.

Smith, A. B. \& Mcgowan, A. J. (2005). Cyclicity in the fossil record mirrors rock outcrop area. Biological Letters 2, 1-3.

Smith, A. B. \& Mcgowan, A.J. (2007). The shape of the Phanerozoic palaeodiversity curve: how much can be predicted from the sedimentary rock record of western Europe. Palaeontology 50, 765-774.

Smith, A. G., Smith, D. G. \& Funnell, B. M. (1994). Atlas of Mesozoic and Cenozoic coastlines. Cambridge University Press, Cambridge.

Sullivan, R. M. (2006). The shape of Mesozoic dinosaur richness: a reassessment. New Mexico Museum of Natural History and Science Bulletin 35, 403-405.

Tarver, J. E., Braddy, S. J. \& Benton, M. J. (2007). The effects of sampling bias on Palaeozoic faunas and implications for macroevolutionary studies. Palaeontology 50, 177-184.

TAYlor, M. P. (2006). Dinosaur diversity analysed by clade, age, place and year of description. In Ninth international symposium on Mesozoic terrestrial ecosystems and biota: abstracts and proceedings (Barrett, P. M. \& Evans, S. E., eds.), pp. 134-138. The Natural History Museum London, UK.

Tipper, J. C. (1979). Rarefaction and rarefiction - the use and abuse of a method in paleoecology. Paleobiology 5, 423-434. 
Tomida, Y. \& Tsumura, Y. (2006). A partial skeleton of titanosaurian sauropod from the Early Cretaceous of Toba City, central Japan. In Proceedings of the 2006 Goseong International Dinosaur Symposium (LEE, Y.-N., ed.), pp. 217-238. Journal of the Paleontological Society of Korea 22.

Trujillo, K. G., Chamberlain, K. R. \& Strickland, A. (2006). Oxfordian U/Pb ages from SHRIMP analysis for the Upper Jurassic Morrison Formation of southeastern Wyoming with implications for biostratigraphic correlations. Geological Society of America Abstracts with Programs 38, 7A.

Twitchett, R. J., Wignall, P. B. \& Benton, M.J. (2000). Discussion of Lazarus taxa and fossil abundance at times of biotic crisis. Fournal of the Geological Society, London 157, 511-512.

Uhen, M. D. \& Pyenson, N. D. (2007). Diversity estimates, biases, and historiographic effects: resolving cetacean diversity in the Tertiary. Palaeontologia Electronica 10, 11A:22p.

UPCHURCH, P. (1995). Evolutionary history of sauropod dinosaurs. Philosophical Transactions of the Royal Society of London, Series B 349, 365-390.

Upchurch, P. \& Barrett, P. M. (2005). A phylogenetic perspective on sauropod diversity. In The Sauropods: evolution and paleobiology (Curry-Rogers, K. A. \& Wilson, J. A., eds.), pp. 104-124. University of California Press, Berkeley.

Upchurch, P., Barrett, P. M. \& Dodson, P. (2004). Sauropoda. In The Dinosauria, $2^{\text {nd }}$ Edition (Weishampel, D. B., Dodson, P. \& Osmólska, H., eds.), pp. 259-322. University of California Press, Berkeley.

Upchurch, P., Barrett, P. M. \& Galton, P. M. (2007). The phylogenetic relationships of basal sauropodomorphs: implications for the origin of sauropods. In Evolution and palaeobiology of early sauropodomorph dinosaurs (BARRETT, P. M. \& Batten, D.J., eds.), pp. 57-90. Special Papers in Palaeontology 77.

Upchurch, P., Hunn, C. A. \& Norman, D. B. (2002). An analysis of dinosaurian biogeography: evidence for the existence of vicariance and dispersal patterns caused by geological events. Proceedings of the Royal Society of London, Series B 269, 613-622.

Upchurch, P. \& Mannion, P. D. (2009). The first diplodocid from Asia and its implications for the evolutionary history of sauropod dinosaurs. Palaeontology 52, 1195-1207.

VAlentine, J. W. (1985). Phanerozoic diversity patterns: Profiles in macroevolution (Geology \& Paleontology). Princeton University Press, New Jersey.

VermeiJ, G. J. (1983). Intimate associations and coevolution in the sea. In Coevolution (Futuyma, D. J. \& Slatkin, M., eds.), pp. 311-327. Sinauer Associates Incorporated, Sunderland, MA.

Vermeij, G. J. \& Leighton, L. R. (2003). Does global diversity mean anything? Paleobiology 29, 3-7.

Wagner, P. J. (1995). Diversification among early Paleozoic gastropods - contrasting taxonomic and phylogenetic descriptions. Paleobiology 21, 410-439.

Wagner, P. J. (2000a). Phylogenetic analyses and the fossil record: tests and inferences, hypotheses and models. Paleobiology 26, $341-371$.

WAgner, P.J. (2000b). The quality of the fossil record and the accuracy of phylogenetic inferences about sampling and diversity. Systematic Biology 49, 65-86.

Wall, P. D., Ivany, L. G. \& Wilkinson, B. H. (2009). Revisiting Raup: exploring the influence of outcrop area on diversity in light of modern sample-standardization techniques. Paleobiology $35,146-167$.
WAnG, S. C. \& Dodson, P. (2006). Estimating the diversity of dinosaurs. Proceedings of the National Academy of Sciences, USA 103, 13601-13605.

Weishampel, D. B., Barrett, P. M., Coria, R. E., Le Loeuff, J., Gomani, E. S., Zhao, Z., Xu, X., Sahni, A. \& Noto, C. $(2004 a)$. Dinosaur distribution. In The Dinosauria, $2^{\text {nd }}$ (Weishampel, D. B., Dodson, P., \& Osmólska, H., eds.), pp. 517-606. University of California Press, Berkeley.

Weishampel, D. B., Dodson, P. \& Osmólska, H. (2004b). The Dinosauria ( $2^{\text {nd }}$ Edition). University of California Press, Berkeley.

Weishampel, D. B. \& Horner, J. R. (1987). Dinosaurs, habitat bottlenecks, and the St. Mary River Formation. Fourth international symposium on Mesozoic terrestrial ecosystems and biota: short papers (Currie, P.J. \& Koster, E. H., eds.), pp. 224-229. Royal Tyrell Museum, Drumheller.

Weishampel, D. B. \& Jianu, C.-M. (2000). Planteaters and ghost lineages: dinosaurian herbivory revisited. In The Evolution of Herbivory in Terrestrial Vertebrates. Perspectives from the Fossil Record (Sues, H.-D., ed.), pp. 123-143. Cambridge University Press, Cambridge.

Westrop, S. R. \& Adrain, J. M. (1998). Trilobite alpha diversity and the reorganization of Ordovician benthic marine communities. Paleobiology 24, 1-16.

Wills, M. A. (2002). The tree of life and the rock of ages: are we getting better at estimating phylogeny? Bioessays 24, 203-207.

Wills, M. A. (2007). Fossil ghost ranges are most common in some of the oldest and some of the youngest strata. Proceedings of the Royal Society of London, Series B 274, 2421-2427.

Wills, M. A., Barrett, P. M. \& Heathcote, J. F. (2008). The modified gap excess ratio (GER*) and the stratigraphic congruence of dinosaur phylogenies. Systematic Biology 57, 891-904.

Wilson, J. A. (2002). Sauropod dinosaur phylogeny: critique and cladistic analysis. Zoological Fournal of the Linnean Society 136, $217-276$.

Wilson, J. A. (2005). Redescription of the Mongolian sauropod Nemegtosaurus mongoliensis Nowinski (Dinosauria: Saurischia) and comments on Late Cretaceous sauropod diversity. Fournal of Systematic Palaeontology 3, 283-318.

Wilson, J. A. \& Sereno, P. C. (1998). Early evolution and higherlevel phylogeny of the sauropod dinosaurs. Society of Vertebrate Paleontology Memoir 5 (Supplement to no. 18), 1-68.

Wilson, J. A. \& Upchurch, P. (2003). A revision of Titanosaurus (Dinosauria Sauropoda), the first 'Gondwanan' dinosaur genus. Fournal of Systematic Palaeontology 1, 125-160.

Wilson, J. A. \& Upchurch, P. (2009). Redescription and reassessment of the phylogenetic affinities of Euhelopus zdanskyi (Dinosauria: Sauropoda) from the Late Jurassic or Early Cretaceous of China. Fournal of Systematic Palaeontology 7, 199-239.

YATES, A. M. (2003). A new species of the primitive dinosaur Thecodontosaurus (Saurischia: Sauropodomorpha) and its implications for the systematics of early dinosaurs. Fournal of Systematic Palaeontology 1, 1-42.

Yates, A. M. (2004). Anchisaurus polyzelus (Hitchcock): the smallest known sauropod dinosaur and the evolution of gigantism among sauropodomorph dinosaurs. Postilla 230, 1-58.

YATES, A. M. (2007). The first complete skull of the Triassic dinosaur Melanorosaurus Haughton (Sauropodomorpha: Anchisauria). In Evolution and palaeobiology of early sauropodomorph dinosaurs (Barrett, P. M. \& Batten, D. J., eds.), pp. 9-55. Special Papers in Palaeontology 77.

Yates, A. M. \& Kitching, J. W. (2003). The earliest known sauropod dinosaur and the first steps towards sauropod 
locomotion. Proceedings of the Royal Society of London, Series B 270, $1753-1758$.

ZhAO, X.-J. (1993). A new mid-Jurassic sauropod (Klamelisaurus gobiensis gen. et sp. nov.) from Xinjiang, China. Vertebrata PalAsiatica 31, 132-138. (In Chinese with English summary.)

\section{SUPPORTING INFORMATION}

Additional supporting information may be found in the online version of this article.
Appendix. S1. Excel spreadsheet listing diversity and sampling data, residuals and rarefaction calculations and all references used to investigate sauropodomorph diversity.

Please note: Wiley-Blackwell are not responsible for the content or functionality of any supporting materials supplied by the authors. Any queries (other than missing material) should be directed to the corresponding author for the article. 